\title{
Operational deformations in long span bridges
}

\section{James Mark William Brownjohn}

Vibration Engineering Section,

College of Engineering, Mathematics and Physical Sciences

University of Exeter,

North Park Road,

Exeter EX4 4QF

Tel: +4401392723698

j.brownjohn@exeter.ac.uk

http://vibration.ex.ac.uk/page/james-brownjohn/

\section{Ki-Young Koo}

Vibration Engineering Section,

College of Engineering, Mathematics and Physical Sciences

University of Exeter,

North Park Road,

Exeter EX4 4QF

Andrew Scullion

Humber Bridge Board, UK

David List

Tamar Bridge and Torpoint Ferry, UK 


\section{ABSTRACT:}

Long span bridges deform quasi-statically and dynamically under a range of operational conditions including wind, traffic and thermal loads, in varying patterns, at different timescales and with different amplitudes.

While external loads and internal forces can only rarely be measured, there are well-developed technologies for measuring deformations and their time and space derivatives. Performance data can be checked against design limits and used for validating conceptual and numerical models which can in turn be used to estimate the external loads and internal forces.

Changes in performance patterns and load-response relationships can also be used directly as a diagnostic tool, but excessive deformations themselves are also a concern in terms of serviceability.

This paper describes application of a range of measurement technologies, focusing on response to extreme loads, for suspension bridges over the River Tamar (with 335m main span) and Humber (with 1410m man span). The effects of vehicular, thermal and wind loads on these very different structures are compared, showing that apart from rare extreme traffic and wind loads, temporal and spatial temperature variations dominate quasi-static response.

Observations of deformation data and sensor performance for the two bridges are used to highlight limitations and redundancies in the instrumentation. 


\section{RELEVANCE OF DYNAMIC SND STATIC BRIDGE DEFORMATION MEASUREMENTS}

Deformation measurements play a critical role in structural identification of bridges (Catbas et al. 2013) through both short measurement campaigns and long term monitoring.

In the form of direct measurements of vertical deflection during a vehicle load test (Calçada et al. 2005), deformation data are used to calibrate design and demonstrate fitness for purpose. In the form of accelerations recorded during modal testing (Ren et al. 2004; Kim et al. 2007; Pakzad et al. 2008; Brownjohn et al. 2010) they provide a direct view of the stiffness and mass properties and their distributions.

These two types of short-term measurement campaigns (load test and modal survey) together with standard assessment tools provide a wealth of information about the state of a structure. All these elements were deployed in a 2010 exercise on US202 bridge 1618-150 in New Jersey (Aktan 2011) where a range of deformation measurement technologies were demonstrated. For example load tests typically employ close-range LVDTs or potentiometers when a fixed reference below the bridge is available, and more exotic noncontacting sensors such as GPS when there is no such fixed base, the usual case for long span bridges.

For longer term measurements as part of a bridge structural health monitoring (SHM) system (Ko and Ni 2005), fewer accelerometers can be deployed, particularly where a modal survey has provided a set of vibration modes (Brownjohn et al. 2010) that can be used as a basis set for mapping a minimal set of measurements to a complete structure. Conversely identification of the more complex quasi-static three dimensional deformation patterns requires a more extensive set of instrumentation.

This aim of this paper is to address the particular issue of identifying the nature of such deformations in long span bridges during normal operation but over long enough periods to capture typical and extreme conditions, providing a useful comparison of their levels and likelihoods. This requires continuous automated capture of deformations and rotations having periods spanning the dynamic range of time scales (where inertia forces are significant) through sub-dynamic (as induced by vehicles and wind gusts) to the daily (weather dependent) and seasonal (climate dependent) range. Along with the wide range of time scales, demanding appropriate frequency response and sample rates, deformations range from microns to meters. Selecting appropriate instrumentation to operate over these time and length scales is a challenge for SHM system designers, 
with choice depending on the nature of the structure and loading, as well as cost, logistical constraints and purposes of the system.

\section{CURRENT VIABLE TECHNOLOGIES FOR MEASURING BRIDGE DEFORMATION}

The earliest methods for continuously measuring and monitoring long span bridge deformations included the use of motion pictures e.g. to study the aero-elastic problems at Tacoma Narrows Bridge (Washington 1954) and hydrostatic leveling e.g. to check effects of structural changes to D. Luiz I bridge, Porto (Marecos 1978). A sophisticated opto-mechanical system was the preferred solution for the deflection measurements of the Tagus River suspension bridge during a remarkably comprehensive exercise of instrumentation and proof load testing in 1966 (Marecos et al. 1969).

Before widespread use of GPS, opto-electronic technologies were developed for long span bridges. For example, lasers were used to track vertical and lateral movement in performance of the Foyle Bridge in Northern Ireland, (Sloan et al. 1992), and LED-based systems were used in Scandinavian bridges (Myrvoll et al. 1994).

Two radically different technologies were employed in the Humber Bridge monitoring campaign of 1990/1991 (Stephen et al. 1993; Zasso et al. 1993). The single axis 'optometer' (Zasso et al. 1993) used for automated monitoring at Humber employed high contrast targets, CCD arrays and threshold detection for tacking transverse and vertical motion separately. A system based on post-processed pattern recognition and trajectory prediction was used for tracking both axes simultaneously and was subsequently developed for automated real-time tracking of the Second Severn Crossing (Macdonald et al. 1997).

There have been experimental GPS applications in the UK, e.g. at Humber (Ashkenazi and Roberts 1997) and Forth (Roberts et al. 2006) but apparently until 2011 no permanent GPS installation on a bridge. However, GPS has for the last decade been the standard choice for deformation measurements on long span bridges in the Far East. Examples include the networks of bridges operated by Nanjing's Jiangsu Transportation Institute and Hong Kong Highways Dept. (Wong 2007), whose designs have been updated for the Forth Replacement Crossing (Kite et al. 2010). 
Robotic total stations (RTS) are still rare for permanent instrumentation of long span bridges, exceptions being the Jiangyin Bridge (Zhou et al. 2006) and the Tamar Bridge described here. However some short term evaluations have been reported (Erdoğan and Gülal 2011; Stiros and Psimoulis 2012).

GPS is now regarded as a mature technology, alongside extensometers, inclinometers and lasers of various forms. Hydrostatic level sensors (as originally used on Tamar and Tsing Ma bridges) are hardly used these days outside Portugal.

All of these instruments have been used for direct measurement of translational deformations; complementary to these there exist technologies already in use for several decades such as LVDTs and inclinometers for measuring small relative motions between components within a structure.

High quality accelerometers can also be used for quantifying the quasi-static deformations patterns due to slowly varying operational loads that do not engage inertia effects. Good low-noise accelerometers that have capability to measure down to ' $\mathrm{DC}$ ' or $0 \mathrm{~Hz}$ can be used to recover translations in the sensing axis through double integration, but noise imposes a limit on the lowest frequency recoverable. DC units can also measure tilt (inclination), but when translations occur at similar low frequencies as the simultaneous rotations the two effects may not easily be distinguished (Rainer 1985; Hjorth-Hansen and Niggard 1977).

Some exemplar permanent deformation monitoring systems are summarized in. Table 1; the majority of these have been in the Far East.

\section{MONITORING OF TAMAR AND HUMBER BRIDGES}

With the aim of describing the capabilities and limitations of the technologies mentioned above, deformation monitoring systems on two long span bridges in the UK are presented. A secondary aim of the paper is to compare and contrast the ways in which these two bridges deform due to operational loads, providing instructive examples of some extreme performance compared with normal ranges, and guidance to inform choice of instrumentation on new bridge projects.

\subsection{Deformation monitoring of Tamar Bridge}

Tamar Bridge (Figure 1) has provided a useful experience in deformation tracking technologies. Built in 1961 as a conventional suspension bridge with a steel truss and $335 \mathrm{~m}$ main span it provides a link between Plym- 
outh (east, in Devon) and Saltash (west, in Cornwall). To cope with heavier vehicles the bridge was 'strengthened and widened' in 2000 by radical alterations that included replacing the deck, adding extra lanes cantilevered either side of the truss and around the tower pylons (clearly visible in Figure 1) and adding a set of 18 stay cables to carry the extra load and restore the camber. Two of these cables are installed in inverted Ushaped troughs providing extra stiffening below the lower chords of the truss girder..

Boundary conditions for longitudinal movement at the towers were also altered so that the cantilevers provide axial continuity from the Plymouth side tower (where main cables reach deck level) to the Saltash tower where expansion joints are installed. To track the effects of the changes during and after the construction, Fugro Ltd installed a structural monitoring system (SMS). This is a comprehensive array of sensors including load cells in all 18 additional stays, wind sensors at three locations, temperature sensors for air, main cable, deck and truss elements, and a hydrostatic leveling system, amounting to a total of 70 data channels.

\subsubsection{Fugro level sensor}

This system comprised a fluid based system with pipes along the main span and pressure sensing stations (LSS) at 1/8 span centres. The system was based on the similar system previously installed by Fugro on bridges in the Lantau Fixed Crossing. The height measurements were specified to be accurate to $+/ 5 \mathrm{~mm}$ and while in principle the pressure changes due to level variations should depend only on velocity of pressure waves in the fluid, the acquisition updates every 10 seconds. The system was overhauled in 2007 , but no longer functions.

Figure 2 shows level data for $\mathrm{h} 71$, at 3/8 span position from the Plymouth side, for a complete 24 hour period (upper plot), then for the rush hour period 4PM to 5PM (lower plot). The sampling rate is too slow to identify passage of individual heavy vehicles, which at the posted $13.4 \mathrm{~m} / \mathrm{sec}$ speed limit would take 25 seconds to cross the bridge. While the drifting and jumping of level signals did not allow for reliable long-term tracking over periods of more than a month, it was possible to apply principal component analysis to the seven-component time series. Figure 3 shows the eigenvector corresponding to the first (strongest) principal component of vertical plane deformation. This pattern operates on a daily cycle, primarily driven by temperature, and there is a clear lop-sided pattern resulting from the hybrid structural form and expansion joint arrangement. 


\subsubsection{Accelerometers and extensometers}

In a sequence of upgrades starting in 2006 the Vibration Engineering Section (VES) installed various dynamic and static instrumentation components to monitor the deformation behavior of the bridge.

A dynamic data acquisition system (DAQ) was installed in 2006 comprising a set of three Honeywell QA750 servo-accelerometers mounted close to midspan. Two units (VS and VN) mounted vertically on the north and south sides of the truss measure vertical acceleration with one unit $(\mathrm{H})$ measuring horizontal acceleration. They are primarily used for tracking vibration response levels and identifying modal parameters but the $\mathrm{H}$ signal can also be used to track rotation of the main span about the long axis. Since the level sensors and the total station reflectors that superseded them measure only on the south side, accelerometers provide the only means of kinematically connecting the two sides of the bridge. In addition a set of eight QA650 servo-accelerometers arranged in biaxial pairs was used to study rain-wind induced vibrations of four of the additional stay cables but these have now been removed since the cables have been fitted with dampers. While installed they provided indirect estimates of the stay cable tensions, useful for corroborating load cell data, with spot checks for the other 12 above-deck stay cables were made by roving a single accelerometer.

Three DAQ channels were also originally used to record extensions at the Saltash Tower expansion joint, using ASM WS12 mechanical (wire) potentiometers (Figure 4). Signals from the complete set of units were available only for a short period and showed that axial separation between Saltash Tower and the main span (north and south sides) closely followed the separation between the spans i.e. that tower-sidespan motion was negligible. Mechanical disruption to the wire threads (due to birds, workers) caused loss of all signals from March 2007 until 2010 when an electrically decoupled wireless link was established to record the relative motion between tower and main span.

\subsubsection{Total positioning system (TPS)}

From the information provided by the hydrostatic leveling system and the Saltash tower extensometers extensometer during 2006 and 2007 it was clear that movement of the bridge in the vertical plane, mostly due to thermal expansion, comprised an axial extension of the girder and a lowering of the suspended structure. To study this two-dimensional motion (and to include transverse motion) a TPS was installed, comprising a Leica 
TCA1201M robotic total station (RTS) and a set of 15 reflectors (Figure 5). TPS was chosen following advice from Graz Institute of Engineering Geodesy and Measurement Systems in preference to GPS due to the expected small movements and the lower cost for multiple measurement positions, there being no need for the 'dynamic' sample rates (1Hz or more) offered by GPS.

The upper portal of the Plymouth Tower provides the best viewpoint for targets on the deck and at reference points, but longitudinal sway prevented a stable vertical plane alignment. The only secure and viable location for the RTS is the roof of the control room adjacent to the roadway, for which the line of sight for distant reflectors around roadway level at the Saltash end results in small angular differences and occasional failure to identify and locate reflectors. This is a secure and convenient location but not optimal in terms of stability and target visibility since with heavy rain, fog and drizzle location capability is also reduced, resulting in patchy data worse than Figure 6. There are also several practical problems with the RTS unit, including cleaning the casing and servicing the mechanical parts.

The RTS data sampling in time and space is sparse even compared to the level sensors but the RTS has the advantage of $3 \mathrm{D}$ coverage that includes towers. Cross-validation between the two systems during the brief period when both were operational shows an exact linear relationship with unit slope (but considerable scatter).

\subsection{Deformation monitoring of Humber Bridge}

The Humber Bridge, opened in 1981, has a main span of $1410 \mathrm{~m}$ and side-spans of $280 \mathrm{~m}$ and $530 \mathrm{~m}$ aligned almost exactly north-south linking the small towns of Hessle and Barton (south). Aerodynamic steel box sections are $22.5 \mathrm{~m}$ wide and $4.5 \mathrm{~m}$ deep with $3 \mathrm{~m}$ walkway cantilevers each side, and were prefabricated in $18 \mathrm{~m}$ long sections with transverse bulkheads at $4.5 \mathrm{~m}$ centres. Tapering reinforced concrete towers are $151.5 \mathrm{~m}$ high and support twin $0.29 \mathrm{~m}^{2}$ main cables with sag of $115.5 \mathrm{~m}$ that in turn support the box deck via inclined hangers. Humber was the world's longest span until 1998 but is now surpassed, most notably by Great Belt and Akashi bridges, so that in 2013 it ranks as the $7^{\text {th }}$ longest span.

\subsubsection{Previous measurement campaigns}

Humber Bridge has provided many opportunities and applications for deformation measurements. The original ambient vibration study (Brownjohn et al. 1987) and the 1990/1991 extended monitoring (Brownjohn et al. 1994) served the purpose of validating simulation software to be used for analysis and design of other 
bridges. Specifically, the finite element analysis procedure validated in the 1985 test was used for studying seismic response of the two Bosporus crossings (Dumanoglu et al. 1992; Dumanoglu and Severn 1987), while the 1990/1991 study validated procedures for simulating the in-wind performance of the proposed Messina Straits Bridge (Diana et al. 2003).

The 1990/1 measurement campaign featuring the use of the two previously mentioned optical tracking systems (Stephen et al. 1993; Zasso et al. 1993) allowed for 2D deflections perpendicular to line of sight to be measured. Combined with mechanical potentiometers measuring motion between the main span and towers and inertial sensors (accelerometers and inclinometers) characterizing transverse, vertical and torsional motion, the 1990/1 study identified relationships between loads and response presented in Table 2. Being operational only during the spring/summer periods of two years, the system missed opportunities to capture seasonal effects and some extreme events, moreover the technology for recovering dynamic (modal) properties left some open questions about lateral oscillations.

\subsubsection{Present technology}

The present exercise extends and simplifies the capabilities of the earlier system and provides useful management data for Humber Bridge Board (HBB), allowing them to make informed decisions on management and intervention. Figure 7 shows the present monitoring system and a sample of sensors. Operational in stages since September 2010, the system comprises the following components:

- GPS base station and two rovers mounted (GMX902 GPS) on the main cables at midspan plus a Nivel 220 inclinometer inside the box girder at midspan (operational since May 2011).

- Three QA750 accelerometers mounted inside the steel box girder at midspan in the same configuration as Tamar (i.e. vertical at east and west extremes, also one horizontal sensor), plus a single RM Young 05305 anemometer mounted on a lamppost.

- Four laser extensometers (Hilti PD4 analog devices converted to digital outputs) were installed at the main span ends at the lower portal beam level adjacent to the bearings, two at each (south and north) tower, with one at each of the east and west ends of the lower tower portal beam (operational 23 Feb 2011 to 27 July 2011 then from November 2012). The extensometers were arranged to measure movement of the main span ends away from the towers. 
- Thermistors installed at four locations around one $18 \mathrm{~m}$ box section (operational from 11 July 2010) supplement signals from HBB. These include additional sensors for air speed, direction and temperature. HBB temperature sensors on the deck surface and structure were also available until October 2012.

As with Tamar Bridge, data fusion is a major concern. Signals from the inclinometer and GPS receivers are recorded at $1 \mathrm{~Hz}$ sample rate and managed using Leica GNSS Spider and Spider QC software. Real-time kinematic (RTK) solutions that apply corrections based on known position of the GPS base station are saved. The Leica software operates on a National Instruments embedded PC that also runs a LabVIEW virtual instrument recording signals from accelerometers and the anemometer at $8 \mathrm{~Hz}$.

Extension and temperature signals are streamed directly to internet so do not rely on the embedded PC, likewise data feeds from weather and temperature sensors installed by HBB go directly to the Sheffield server for processing.

As with Tamar Bridge, automated batch routines process and fuse the data streams into 30-minute summary values which are saved to a common time-base and can be accessed using a web-based viewer or a MATLAB interface.

While acceleration data have been recorded almost continuously, there have been data gaps for other deformation sensors. The extensometer interface software has recently been upgraded by HBB and access routes to HBB wind and temperature data have changed, while an extreme wind event destroyed the RM Young anemometer in early 2013. The signal cable to the east GPS antennae was vandalized in late 2012 (and repaired ne year later), but due to the kinematic relationships already established this was not a serious concern. Despite the practical problems, sufficient data for representative periods have been collected to characterize the bridge deformation mechanisms and the system is maintained to continue providing performance data.

Compared to the 1990/1991 optical deformation system, exercise, GPS is a more reliable and practical system for positional tracking, using four extensometers has provided valuable information about the horizontal plane movement of the main span and more comprehensive data are available about structural temperature. There has also been a greater focus on rotations about all axes, and with more sophisticated modal analysis procedures, it has been possible to examine variations in and causality of modal parameter variations with greater confidence. 


\section{RESPONSE RANGES AND CORRELATIONS}

\subsubsection{Tamar Bridge}

For Tamar Bridge, wind effects are apparently relatively insignificant, so Figure 8 gives an impression of deformation ranges and effects of structural temperature variation. Temperature increase directly drives axial extension (which correlates well with deck temperature) and main cable extension (which of course correlates

well with main cable temperature. The relationships are not quite linear, particularly for temperatures above (approximately) $15^{\circ} \mathrm{C}$ on exposed parts of the structure where clear skies in summer result in large temperature variations across a section.

For increasing temperature, increasing tensions for stay cables P2 and P4 attached to the Plymouth Tower contrasts with reducing tensions for stays S2 and S4 attached to the Saltash Tower as main span extension brings it closer. This effect contributes to the lop-sided main span deformation pattern seen in Figure 3, and the breadths of the two groups of data points indicate hysteretic effects due to small time delays in the relationships.

\subsubsection{Humber Bridge}

Some interesting relationships between response quantities and environmental loads are summarised in Figure 9 for wind and Figure 10Error! Reference source not found. for temperature.

During two years of monitoring winds have caused the largest and most interesting deformations, with 30minute average speeds up to $28 \mathrm{~m} / \mathrm{sec}$ and instantaneous values exceeding $39 \mathrm{~m} / \mathrm{sec}$ (hurricane force). Temperatures have ranged from $-8^{\circ} \mathrm{C}$ to $49^{\circ} \mathrm{C}$ for deck surfacing temperatures and from $-6.5^{\circ} \mathrm{C}$ to $30.3^{\circ} \mathrm{C}$ for air temperatures, all greater than ranges experienced at Tamar.

Lateral (sway) deformation and main span rotation Figure 9 show that it moves away from the wind (negative normal wind is from the west) and dips on the leading edge. In fact wind also induces downwards deck displacement due to the inverted aerofoil shape, but such displacements are generally smaller than those due to either temperature or vehicle effects, only being noticeable during the strongest winds. There is also a small axial movement linked to lateral sway. In fact during strong winds it appears that the whole suspended structure shifts north in westerly winds or south in easterly winds. 
Temperature effects are also very clear (Figure 10). Main span vertical displacement and expansion, appearing as reduction of extensometer signals, follow temperature, with slope depending on which temperature reading is used. Unlike Tamar Bridge, no main cable temperature data are available and 'surface' temperature is for a sensor buried in the deck surfacing, while 'box top' is a few cm below on the inside top surface of the steel box. The internal temperature data provide the cleanest correlation but were not available for much of the time that all four extensometers were operational. Hence the last (right) plot uses surface temperature to compare axial motion of the deck for bearings at each end along with the GPS northings at midspan. Extension is more or less even between the two ends and the GPS shows only a moderate northerly shift at midspan with temperature increase. Along with the wind effect on northings this suggests mechanisms relating to the asymmetry of the span configuration.

\section{DYNAMIC DISLACEMENTS}

While accelerations may often be dominated by high frequency vibrations excited as a result vehicles reacting to uneven pavement, these translate to insignificant displacements and the greatest contributions are at the fundamental mode frequencies of each type: lateral (L), vertical (V) and torsional (T), and which for these bridges the mode shapes are either symmetric (S) or approximately symmetric about midspan.

Standard deviation, or de-trended root mean square (RMS) of modal displacement is taken to represent the strength of a response in a vibration mode and is derived from RMS of Fourier acceleration amplitudes close to the modal frequency divided by the relevant squared circular frequency. Figure 11 shows the distribution (probability density function) of 30-minute RMS displacements for the fundamental modes of each type in each bridge.

The dynamic behavior of the two bridges is radically different and impacts on the ranges of displacements experienced in vibration modes. Mode frequencies (given in the figure) are much lower for Humber and the displacements are by far the largest, the largest RMS value having been obtained for lateral direction for an extreme wind event. Tamar modal displacements are insignificant compared to quasi-static values while for Humber, lateral vibrations in wind are significant, as study of extreme wind events will later show. 
These values do not reflect the overall ranges due to quasi-static components, however for random vibration of approximately constant level during the 30-minute averaging period, the peak factor scaling RMS to maxima is approximately 3 .

\section{EXTREME RESPONSE EVENTS}

The most revealing performance information derives from extreme (operational) loading events e.g. strong winds, low or high temperatures, weak or strong sunlight and exceptional vehicle loads.

Significant temperature effects on Tamar Bridge deformation have already been shown via the correlation plots and the only noticeable effect of wind has been increased acceleration response in the lower vibration modes for mean wind speeds exceeding $10 \mathrm{~m} / \mathrm{sec}$. Hence the main interest with wind is at Humber Bridge where aero-elastic wind-structure interaction results in observable changes in modal properties (Diana et al. 1992) as well as significant dynamic and quasi-static deformations.

Both structures have experienced extreme traffic loads, usually due to multiple vehicles in traffic jams. Tamar Bridge experienced a single 300 tonne vehicle in 2010 (Westgate et al. 2013), while Humber regularly experiences abnormal loads of around 100 tonnes.

\subsection{Heavy vehicle crossing}

The single most significant loading event during the monitoring of Tamar Bridge was the passage of a two-tractor low-loader carrying a power station component, with total vehicle weight of 300 tonnes ( 
Figure 12). To track the vehicle the RTS was reconfigured to track a single target at the fastest rate possible, while a second standalone RTS (Leica TS30) was deployed to track Saltash Tower top deflections, also using a single reflector. Other response parameters such as extension, cable tension and acceleration were simultaneously recorded.

Experimentation with the two RTS units determined that they could operate at sample rates up to 3 Hz. Saltash expansion joint extension and stay cable tension data were interpolated at this rate and merged with the RTS data to produce the plots of 
Figure 13. The whole vehicle crossing event lasted 3.5 minutes and the recorded peak midspan vertical deflection of $300 \mathrm{~mm}$ corroborated the authors' and the consultant's predicted values.

For Humber Bridge, the heaviest vehicle was observed during the 1990 monitoring campaign (Brownjohn et al. 1994). The 172 tonne vehicle generated a midspan vertical deflection of just over 400mm, in fact smaller than deflections due to strong winds and normal temperature variations. From the present campaign, Figure 14 shows the clear effects of heavy vehicles crossing in both directions via the main span deformations captured using several sensor types and recorded during low-wind conditions. The largest deformations during this interval are due to a 110 tonne vehicle, logged by an independent off-bridge weigh-in-motion station. The vertical deformation from midspan GPS is clear, as are the rotations provided by differencing the GPS heights across the deck. The rotations are corroborated by horizontal accelerometer and Nivel inclinometer signals converted to height differences across the same separation as the GPS antenna. A notable effect, similar to that observed at Tamar Bridge is the corresponding northerly movement of the main span followed by a southerly over-correction for southbound vehicles (and vice-versa). This effect has contributed strongly to wear of Humber A-frame bearings.

\subsection{Traffic Jam}

Traffic jams also produce large and anomalous deformations and can be of particular concern to bridge operators when they coincide with extreme temperatures.

Figure 15 shows deck rotations derived from DC component of lateral acceleration and changes in stay cable tension during one event in on Tamar Bridge in April 2011 when neither the level system nor the RTS were in operation. Tension variations in the two stay cable pairs normally go in opposite directions due to deck expansion (as in the middle plot as the day progresses) but in this case their simultaneous increase around 9AM appears as a clear anomaly. The automated modal analysis system also detected noticeable dips in mode frequencies due to the added mass of the vehicles.

For Humber Bridge traffic jams are rare due to low traffic volume, but one event on April $6^{\text {th }} 2012$ (Figure 16) was clearly identified by anomalous GPS height signals, appearing as $0.5 \mathrm{~m}$ shifts in 30 -minute average values for both sensors. The $1 \mathrm{~Hz}$-sampled raw time series show midspan vertical deflection as well as a rota- 
tion (west side dipped) for about 25 minutes caused by an accident blocking the northbound side of the bridge -while the southbound lanes were open (with spikes caused by heavy vehicles).

\subsection{Extreme winds at Humber}

The greatest static and dynamic deformations recorded at Humber Bridge have been due to wind. Examples are shown for two strong wind events, on May $23^{\text {rd }} 2011$ (maximum mean wind speed $20 \mathrm{~m} / \mathrm{sec}$, maximum gust $30 \mathrm{~m} / \mathrm{sec}$ ) and $30^{\text {th }}$ January 2013 (the $26 \mathrm{~m} / \mathrm{sec}$ mean speed and $39 \mathrm{~m} / \mathrm{sec}$ gust), both for westerly winds (which dominate in the UK).

The event of $23^{\text {rd }}$ May (Figure 17) is characterized by a rising wind speed producing a large midspan lateral deflection followed by strong lateral oscillations. These are accompanied by vertical (downwards) deflections, rotations and longitudinal movement, with GPS northings inverted as 'southings' for comparison with extensions. The inclinometer is not effective at measuring rotations in strong winds the low-range highresolution option installed clips for angles greater 0.0025 radian ( $55 \mathrm{~mm}$ height difference). The January $30^{\text {th }}$ event is exceptional, causing lateral oscillation up to $1 \mathrm{~m}$ amplitude and depression of the box deck by $1 \mathrm{~m}$.

All signals were available for the May 2011 event but the east GPS signal was not available for the January 2013 event, while accelerometer data do not cover the complete event. For both events the extensometer signals are particularly interesting: the difference between the two sensors on east and west sides of the Hessle tower tracks the lateral deflection perfectly, but is approximately one tenth of the lateral deflection. In the figure these differences are superimposed on changes in the averaged extension readings that for $30^{\text {th }}$ January appear as a reduction of $(0.2 \mathrm{~m})$ and which is reflected by a $0.2 \mathrm{~m}$ increase in GPS northings. In other words the whole span shifted north $0.2 \mathrm{~m}$, an effect confirming the observation in Figure 9.

Total accelerations in any direction do not translate directly to displacements but during the two strong wind events, midspan acceleration response reached $0.2 \mathrm{~m} \cdot \mathrm{sec}^{-2}$ vertical amplitude and $0.05 \mathrm{~m} . \mathrm{sec}^{-2}$ lateral amplitude.

\section{HUMBER BRIDGE MAIN SPAN BEARING MOVEMENTS}

Main and side spans of Humber Bridge are constrained against lateral and vertical translation and against rotation about the longitudinal axis by means of a pair of A-frame rockers (Figure 18) at each end, while road- 
way continuity is via Demag expansion joints. The combination w frequenciess designed to allow free axial movement due to vehicles, wind and temperature.

\subsection{Bearing influence on dynamic performance}

The operation of the bearings is known to have a strong influence on the dynamic properties of Humber Bridge. The validated finite element model (Brownjohn et al. 1987) demonstrated that with all bearings behaving as perfect sliding and pinned joints, the first vertical vibration mode would be anti-symmetric, with frequency $0.108 \mathrm{~Hz}$, whereas with either end not free to slide the first mode is the 'symmetric' one. In reality the symmetric mode always appears first at $0.116 \mathrm{~Hz}$, with the anti-symmetric mode at $0.15 \mathrm{~Hz}$ during all vibration measurements since 1985 .

For both Humber Bridge and Tamar Bridge, automated operational modal analysis operates to provide modal parameters for the lowest few vertical, lateral and torsional modes.

For both bridges the first lateral modes (symmetric) modes follow diurnal patterns with ranges up to $20 \%$ of mean values, but the causes are not obvious since temperature, wind and traffic all have diurnal variations. For Tamar Bridge the effect has been shown to be strongly dependent on traffic load (Cross et al. 2013).

For Humber Bridge the effect appears to be amplitude and wind-speed dependent. Modal frequencies and damping ratios for a range of first lateral mode (LS1) RMS response levels are shown in Figure 19. It is clear that modal frequency stabilizes at $0.054 \mathrm{~Hz}$ for high amplitude response. Likewise for strong response damping values drops below $1 \%$ while at low response levels damping can exceed $10 \%$.

The frequency variation/duality for mode LS1 was previously observed in 1988 by Building Reseach Establishment (Littler 1992). It is believed that the damping and frequency trends are consistent with high friction at the bearings that inhibit the differential bearing movement that is linked to lateral deformation of the deck shown in Figure 17.

\subsection{Bearing cumulative movement}

The visible condition of the bearings as shown in Figure 18, and which by the argument above has not affected the global behavior of the bridge, led to a requirement to replace them in 2013 (Hornby et al. 2012). 
Extension data for a period in 2011 were used to inform design through information on the exected travel of the bearing rockers and the bearing replacement is expected to have completed in 2014 .

Figure 20 indicates the extent of this motion for one day each of windy and calm conditions. The slow variations in the extension time series are due to temperature, the faster variations being due to quasi-static wind response then vehicle-induced motion (as in Figure 14), then low frequency vertical and lateral modes.

Clearly strong winds can double the travel, but even for calm days $50 \mathrm{~m}$ of accumulated daily travel amounts to $580 \mathrm{~km}$ over the bridge lifespan to date, probably a little more than anticipated and going towards explaining the bearing condition before replacement. Despite this, there appears to have been no significant change in the effect of bearings on modal properties; first vertical mode frequencies have not changed. Also the quasi-static component of bearing travel is very similar between 1990/1 monitoring (some data from that study are still available) and the recent measurements. Apparently the bearings have been forced to endure the bridge motion, regardless of consequence and the behaviour seems likely not to have changed significantly over the bridge lifetime

\subsection{Response in frequency domain}

Time series of response for a day of moderate winds have been converted to frequency domain to illustrate the performance of different sensors in capturing the quasi-static and dynamic response of Humber Bridge. The result is Figure 21 which covers the frequency range $0.03 \mathrm{~Hz}$ to $2 \mathrm{~Hz}$ with accelerometer signals converted to displacements (through amplitude division by squared circular frequency). Going left to right the plots illustrate vertical, lateral and rotational deformations.

GPS data, which are effectively noise above $0.5 \mathrm{~Hz}$ due to interpolation from the $1 \mathrm{~Hz}$ original sample rate, are really only useful for capturing the first vertical, lateral and torsional modes (VS1, LS1, TS1), and accelerometers do a much better job for dynamic response with clear identification of higher modes.

It is educational that accelerometers capture vertical motion successfully down to $0.03 \mathrm{~Hz}$ and in fact even down to $0.01 \mathrm{~Hz}$. Lateral accelerometer, lateral GPS and inclinometer all pick up the first lateral mode $(0.054$ Hz). The inclinometer ('inc') also picks up some higher lateral modes (e.g. $0.4 \mathrm{~Hz}$ ) seen in the accelerometer signal, showing that it is not decoupled from inertial effects. On the other hand it does not capture the first 
torsional mode TS1 $(0.310 \mathrm{~Hz})$ well. GPS height difference WH-EH $(\delta \mathrm{H}(\mathrm{W}-\mathrm{E})$ in other figures) hardly captures any dynamic response.

\subsection{GPS vs. Accelerometers vs. inclinometers}

Figure 17, Figure 14 and Figure 21 show the potential for estimating deformations using cheaper or more convenient sensors. For example the inclinometer provides practically the same data as the DC component of the lateral accelerometer but little else. Similarly knowing (as a result of this exercise) that height differences between GPS 'rover' receivers either side of the bridge could be estimated using a single rover and the DC component of the lateral acceleration, the second rover appears to be redundant.

There is a strong correlation between lateral movement of the deck and rotation (about a vertical axis) at the deck bearings but the relationship depends on the deformed shape along the deck at high amplitudes when it is presumed the bearings are 'unstuck'. In any case the GPS sensors have so far been more reliable than extensometers. Hence a combination of single GPS, DC accelerometer and a pair of extensometers is about the minimum requirement for capturing quasi-static deck response. A pair of vertical accelerometers completes the picture with dynamic response.

Clearly accelerometers can capture dynamic components of response down to frequencies below the lateral mode frequency $(0.054 \mathrm{~Hz})$ so a relatively expensive GPS rover is an extravagant means for recovering dynamic response. Likewise use of high frequency GPS data (e.g. above $2 \mathrm{~Hz}$ ) to recover dynamic response appears to be pointless, although high frequency capability is improved using averaging and high frequency receivers. For example displacement amplitude of $5 \mathrm{~mm}$, which is a reasonable estimate of the best resolution capability of GPS, translates to an acceleration of $0.8 \mathrm{~m} \cdot \mathrm{s}^{-2}$ at $2 \mathrm{~Hz}$, well above acceleration levels observed in the low frequency modes for both bridges.

The low frequency response of the accelerometer illustrated in Figure 21 was tested to see how well it could reproduce quasi-static vertical motion. Figure 22 shows an attempt using May $23^{\text {rd }} 2011$ data and a high pass filter set at $0.0025 \mathrm{~Hz}$ for the double integration of averaged east and west signals. The right plot compares dynamic components of the signals by applying $0.08 \mathrm{~Hz}$ high pass filters. The timing mismatch could be in part due to use of slightly different filtering and in part due to data acquisition PC clock drift, but the match is convincing and the small differences obvious. 


\section{OVERVIEW OF PERFORMANCE}

Comparison of two bridges and a range of sensors permits the authors to comment on the similarities and differences and the implications for bridge performance monitoring.

\subsection{Sensor performance}

The similarities and differences between the two systems, and their contemporaneous operation provides insights into best approaches for monitoring such structures considering resolution, noise and frequency content as well as cost and operation.

In the higher frequency range, certainly up to no more than $5 \mathrm{~Hz}$ and usually not exceeding $1 \mathrm{~Hz}$ for a long span bridge, information about dynamic (modal) characteristics is relevant to academics but only to a minority of high-end specialist consultants and very well informed bridge operators. Dynamic characterisation serves a purpose in the role of calibrating simulations of dynamic behavior in unusual events such as earthquakes and wind storms and in very limited circumstances can help to identify altered structural condition. At present however, deformations in the sub-modal, quasi-static frequency range tend to be of greatest direct interest as they relate to serviceability in normal operation and are the parameters that designers aim to limit. For some types of response, deformations are small and sensor resolution (or threshold) is important, as are noise characteristics.

Noise performance of accelerometers is relatively straightforward to describe. The QA750 accelerometer is reported as having 'resolution/threshold' better than $1 \mu \mathrm{g}$, while our own studies (Brownjohn and Botfield 2009) have shown that broadband noise floor $(0-100 \mathrm{~Hz})$ is $3 \mu \mathrm{msec}^{-2} / \sqrt{\mathrm{Hz}}$ or better. In terms of displacement these figures convert to $2.5 \mathrm{~mm}$ resolution and $0.75 \mathrm{~mm} / \sqrt{ } \mathrm{Hz}$ noise at $0.01 \mathrm{~Hz}$ and to $0.25 \mu \mathrm{m}$ and 0.075 $\mu \mathrm{m} / \sqrt{ } \mathrm{Hz}$ noise at $1 \mathrm{~Hz}$.

For the Nivel220 inclinometer, in the range setting used here, resolution is $1 \mu \mathrm{rad}$ and accuracy $47 \mu \mathrm{rad}$ (no noise value is quoted by Leica). For the QA750 horizontal accelerometers used in both bridges to indicate tilt, output due to main span rotation $\theta$ is resolved gravity $(\mathrm{g})$ component g.sin $\theta$, so resolution is $1 \mu \mathrm{rad}$ and noise $0.3 \mu \mathrm{rad} / \sqrt{ } \mathrm{Hz}$. 
For ASM W12 mechanical extensometers used at Tamar, electrical noise is quoted which translates to $\sigma=0.16 \mathrm{~mm}$ on extensions, while the Hilti PD4 units at Humber have quoted accuracy of $\pm 2 \mathrm{~mm}$. So while the lasers are more convenient, they are less accurate. More accurate lasers are available but they cannot operate at the $7 \mathrm{~m}$ distance used at Humber Bridge.

Accuracy of the Leica TCA1201M is also clear: $2 \mathrm{~mm}+2 \mathrm{ppm}$ for the electronic distance measurement and 1 arc-second for the theodolite. Hence at the $650 \mathrm{~m}$ distance to the furthest reflector, accuracy is $3.3 \mathrm{~mm}$.

For the GPS, noise, resolution and accuracy are harder to characterize. (Nickitopoulou et al. 2006) suggest standard accuracy of $15 \mathrm{~mm}$ for horizontal measurements and $35 \mathrm{~mm}$ for vertical measurements, both at 98.5\%ile level, without gross errors like cycle slip or multipath. Assuming Gaussian distribution (and GPS noise has unusual characteristics), standard deviation is still more than $5 \mathrm{~mm}$ horizontally and $10 \mathrm{~mm}$ vertically.

The previous short term Humber Bridge GPS campaign (Ashkenazi and Roberts 1997) provided a figure of $1 \mathrm{~mm}$ resolution in horizontal plane and $3 \mathrm{~mm}$ in vertical direction. The differences in Figure 22 suggest a poorer resolution yet the GPS signals still reflect the scale of the bridge motion, and the quality of the data is good enough to provide clear correlations with other load or response parameters.

One way to check GPS performance at Humber would be to examine signals which should be practically identical, e.g. the pairs of northing and easting signals from the east and west receivers. The difference of eastings (sway) for the same data set used for Figure 21 shows typical modal response at $0.22 \mathrm{~Hz}, 0.37 \mathrm{~Hz}$ and $0.49 \mathrm{~Hz}$. None of these frequencies correspond to lateral modes so it is possible that they correspond to 'cable modes' where only the suspension cables participate, the lowest of which was predicted at $0.24 \mathrm{~Hz}$ in the first three-dimensional analytical model study of the bridge (Dumanoglu and Severn 1987). Even with the weak modal response, the two signal differences have $\sigma=2 \mathrm{~mm}$ in the $0.2-0.5 \mathrm{~Hz}$ band.

The $0.15 \mathrm{~m}$ range of vertical deformations at Tamar Bridge seems to have validated original advice against using GPS but a direct comparison would still be useful. For Humber Bridge the range of vertical movements has been $2 \mathrm{~m}$, slightly larger for the lateral direction, and all values are for 30-minute averages. The major advantage of GPS is the uniform sampling rate set at $1 \mathrm{~Hz}$ to capture quasi-static effects of vehicle and wind and provide a cross-check on accelerometer data for lower frequency vibration modes. For both bridges, double 
integration could not capture the quasi-static vehicle-induced vertical deformations, and when tracking multiple targets at Tamar the RTS sample rate is far too slow.

The quasi-static tracking solution for road bridges spans shorter than Tamar Bridge would be either a single target RTS (as deployed for tracking the heavy vehicle) or a purely optical tracking system, which would depend on weather conditions. For longer bridges GPS is ideal since RTS and other optics-based systems suffer with poor visibility conditions and also degrade with distance.

Accelerometers would measure rotation and capture modal response while GPS/RTS would overlap with lower modes and resolve quasi-static response. Hence accelerometer and GPS signals linked e.g. by Kalman filter should be a good approach (Smyth \& Wu, 2007). Neither extensometer system used here was totally satisfactory, so a solution with short range, high resolution lasers would be preferred, preferably at both ends of the span, at either side.

Strain gauges would not have been useful for these deformation measurements since: multiple strain measurements (or assumed uniform strain) would be necessary to estimate e.g. Humber box deck expansion or curvature and such data were available directly from the deformations. The only application in this study was in the 'load cells' for the Tamar additional stay cables, which carry about $10 \%$ of the weight of the suspended structure.

\subsection{Bridge performance}

Tamar Bridge seems relatively immune to extreme weather due to short truss span (reduced wind effect) and more benign temperature climate. Road traffic is much heavier than at Humber and there is also interest in bearing performance due to the effects of the strengthening and widening operation. For this bridge the normal operation is probably the greater interest. Humber Bridge is the more vulnerable to wind effects with some very large deformations, and suffers more extreme temperatures, albeit so far with no adverse effects. Regarding safety this study provides no surprises in the way of unexpected or worrying performance and the monitoring systems are most useful for providing information to support retrofit that for these bridges relates to bearings and deck surfacing. 


\section{CONCLUSIONS}

Concerning bridge deformations, for both bridges the major driver under normal circumstances is temperature, which operates over the slowest timescale of all forms of loading. The deformation patterns induced by variation of temperature in time and position require a combination of sensors to identify them, with focus on movements in the vertical plane. The largest deflections have been due to rare extreme wind events and abnormal vehicles, while deflections due to normal heavy vehicle and strong wind loads at sub-dynamic quasistatic frequencies are smaller than the temperature induced motions. In all but exceptional winds, deformations in individual vibration modes are relatively small.

Identifying these deformations can be demanding for permanent instrumentation systems. GPS appears to be a standard choice for long span bridges, but below a certain span length its reduced compared to opticsbased systems with 3D capability, of which the present best solution is the total station. Accelerometers provide a wealth of data limited only by ability to capture quasi-static response and so investment in high quality devices is worthwhile, while laser or LED-based devices for line of sight measurements should be best suited for the important role of tracking bearing motion. 
Aktan, A.E. 2011. International Bridge Study Workshop. Available at: cait.rutgers.edu/system/files/u5/Aktan_IBS_slides_061311.pptx.

Ashkenazi, V. and Roberts, G.W. 1997. Experimental monitoring of the Humber Bridge using GPS. Proceedings Institution of Civil Engineers, Civil Engineering 120, pp. 177-182.

Brownjohn, J.M.W., Bocciolone, M., Curami, A., Falco, M. and Zasso, A. 1994. Humber Bridge Full-Scale Measurements Campaigns 1990-1991. Journal of Wind Engineering and Industrial Aerodynamics 52, pp. $185-218$.

Brownjohn, J.M.W. and Botfield, T. 2009. A folded pendulum isolator for evaluating accelerometer performance. Experimental Techniques 33(1), pp. 33-37.

Brownjohn, J.M.W., Dumanoglu, A.A., Severn, R.T. and Taylor, C.A. 1987. Ambient vibration measurements of the Humber Suspension Bridge and comparison with calculated characteristics. Proceedings Institution of Civil Engineers Part 2 83, pp. 561-600.

Brownjohn, J.M.W., Magalhães, F., Caetano, E. and Cunha, A. 2010. Ambient vibration re-testing and operational modal analysis of the Humber Bridge. Engineering Structures 32(8), pp. 2003-2018.

Calçada, R., Cunha, A. and Delgado, R. 2005. Analysis of traffic-induced vibrations in a cable-stayed bridge. Part I: experimental assessment. Journal of Bridge Engineering 10(4), pp. 370-385.

Catbas, F.N., Correa-Kijewski, T. and Aktan, A.E. 2013. Structural Identification of Constructed Systems. Approaches, Methods and Technologies for Effective Practice of St-Id. American Society of Civil Engineers.

Cross, E.J., Koo, K.-Y., Brownjohn, J.M.W. and Worden, K. 2013. Long-term monitoring and data analysis of the Tamar Bridge. Mechanical Systems and Signal Processing 35(1-2), pp. 16-34.

Diana, G., Cheli, F., Zasso, A., Collina, A. and Brownjohn, J.M.W. 1992. Suspension bridge parameter identification in full-scale test. Journal of Wind Engineering and Industrial Aerodynamics 41, pp. 165-176.

Diana, G., Falco, M., Cheli, F. and Cigada, A. 2003. The aeroelastic study of the Messina Straits Bridge. Natural Hazards 30, pp. 79-106.

Dumanoglu, A.A., Brownjohn, J.M.W. and R.T., S. 1992. Seismic analysis of the Fatih Sultan Mehmet (Second Bosporus) Suspension Bridge. Earthquake Engineering and Structural Dynamics 21, pp. 881-906.

Dumanoglu, A.A. and Severn, R.T. 1987. Seismic response of modern suspension bridges to asynchronous vertical ground motion. Proceedings Institution of Civil Engineers Part 2 83, pp. 701-730.

Erdoğan, H. and Gülal, E. 2011. Ambient Vibration Measurements of the Bosphorus Suspension Bridge by Total Station and GPS. Experimental Techniques 37(3), pp. 16-23.

Hjorth-Hansen, E. and Niggard 1977. Et akselerometer og dets signalkjede. Trondheim: NTH.

Hornby, S.R., Collins, J.H., Hill, P.G. and Cooper, J.R. 2012. Humber Bridge A-frame refurbishment / replacement. In: Proceedings of the 6th International Conference on Bridge Maintenance, Safety and Management (IABMAS). Stresa, Italy: Taylor \& Francis Group, London, pp. 3170-3177. 
Kim, S., Pakzad, S.N., Culler, D., Demmel, J., Fenves, G., Glaser, S. and Turon, M. 2007. Health monitoring of civil infrastructures using wireless sensor networks. In: Proceedings of the Sixth International Symposium on Information Processing in Sensor Networks (IPSN2007). pp. 254-263.

Kite, S., Carter, M. and Hussain, N. 2010. Forth Replacement Crossing - Design for safe maintenance and management. In: IABMAS2010, Fifth International Conference on Bridge Maintenance, Safety and Management, Philadelphia, Pennsylvania, USA. Philadelphia, PA, USA, pp. 1826-1833.

Ko, J.M. and Ni, Y.Q. 2005. Technology developments in structural health monitoring of large-scale bridges. Engineering Structures 27, pp. 1715-1725.

Koh, H.-M., Lee, H.-S., Kim, S., Choo, J.F., Boller, C., Chang, F.K. and Fujino, Y. 2009. Monitoring of Bridges in Korea. In: Encyclopedia of Structural Health Monitoring. John Wiley \& Sons, pp. 1-23.

Littler, J.D. 1992. Ambient vibration tests on long span suspension bridges. Journal of Wind Engineering and Industrial Aerodynamics (41-44), pp. 1359-1370.

Macdonald, J.H.G., Dagless, E.L., Thomas, B.T. and Taylor, C.A. 1997. Dynamic measurements of the Second Severn Crossing. ICE Proceedings Bridge Transport 123(4), pp. 241-248.

Marecos, J. 1978. The measurement of vertical displacements through water levelling method. Materials and Structures 11(5), pp. 361-370.

Marecos, J., Castanheta, M. and Trigo, J.T. 1969. Field observation of Tagus River suspension bridge. Journal of Structural Engineering 95(4), pp. 555-583.

Myrvoll, F., DiBiagio, E. and Hansvold, C. 1994. Instrumentation for monitoring the Skarnsundet cablestayed bridge. In: Third Symposium on Straits Crossings. Alesund, N. Balkema, pp. 207-215.

Nickitopoulou, A., Protopsalti, K. and Stiros, S. 2006. Monitoring dynamic and quasi-static deformations of large flexible engineering structures with GPS: Accuracy, limitations and promises. Engineering Structures 28, pp. 1471-1482.

Pakzad, S.N., Fenves, G.L., Kim, S. and Culler, D.E. 2008. Design and implementation of scalable wireless sensor network for structural monitoring. Journal of Infrastructure Systems 14(1), pp. 89-101.

Rainer, J.H. 1985. Effect of rotation on motion measurements of towers and chimneys. Ottawa: DBR NRC Building Research Note No. 230.

Ren, W.-X., Harik, I.E., Blandford, G.E., Lenett, M. and Baseheart, T.M. 2004. Roebling suspension bridge. II: ambient testing and live-load response. Journal of Bridge Engineering, 9(2), pp. 119-126.

Roberts, G.W., Meng, X., Brown, C.J. and Andrew, A. 2006. Measuring the movements of the Forth Road Bridge by GPS; lorry trials. In: Kumar, A., Brown, C. J., and Wrobel, L. C. eds. The First International Conference on Advances in Bridge Engineering. Bridges - Past, Present and Future. Uxbridge. pp. 28-36.

Sloan, T.D., Kirkpatrick, J., Boyd, J.W. and Thomson, A. 1992. Monitoring the in service behaviour of the Foyle Bridge. The Structural Engineer 70(7), pp. 130-134.

Smyth A., Wu M, (2007). Multi-rate Kalman filtering for the data fusion of displacement and acceleration response measurements in dynamic system monitoring. Mechanical Systems and Signal Processing 21(2), 706723.

Stephen, G.A., Brownjohn, J.M.W. and Taylor, C.A. 1993. Measurements of static and dynamic displacement from visual monitoring of the Humber Bridge. Engineering Structures 15(3), pp. 197-208. 
Stiros, S. and Psimoulis, P.A. 2012. Response of a historical short-span railway bridge to passing trains: 3-D deflections and dominant frequencies derived from Robotic Total Station (RTS) measurements. Engineering Structures 45, pp. 362-371.

Sumitro, S. 2001. Current and future trends in long span bridge health monitoring system in Japan. NSF Workshop on Health Monitoring of Long Span Bridges, pp. 1-12.

Washington, U. of 1954. Aerodynamic stability of suspension bridges with special reference to the Tacoma Narrows bridge. University of Washington Engineering Experiment Station, Bulletin No. 116.

Westgate, R., Koo, K.-Y., Brownjohn, J.M.W. and List, D. 2013. Suspension bridge response due to extreme vehicle loads. Structure and Infrastructure Engineering, Online, pp. 1-13.

Wong, K.-Y. 2007. Design of a structural health monitoring system for long-span bridges. Structure and Infrastructure Engineering 3(2), pp. 169-185.

Zasso, A., Vergani, M., Bocciolone, M. and Evans, R. 1993. Use of a newly designed optometric instrument for long-term, long distance monitoring of structures, with an example of its application on the Humber Bridge. In: Proceedings, 2nd International Conference on Bridge management. Guildford, pp. 1-10.

Zhou, H.F., Ni, Y.Q. and Ko, J.M. 2006. Analysis of Structural Health Monitoring Data from the Suspension Jiangyin Bridge. In: Guemes, A. ed. Proceeding of the 3rd European Workshop on Structural Health Monitoring. Lancaster, Pennsylvania, USA: DEStech Publications, pp. 364-371. 
Table 1: Example bridge deformation monitoring systems

\begin{tabular}{|c|c|c|c|c|c|c|}
\hline Bridge & span & built & installed & displacement & \multicolumn{2}{|c|}{ GPS inclinometer } \\
\hline Jiangyin $^{1}$ & 1385 & 1998 & 1998,2005 & & 8 & \\
\hline Akashi $^{2}$ & 1991 & 1998 & 1998 & $3 \times \mathrm{ext}$ & 8 & \\
\hline Nahmae $^{3}$ & 404 & 1973 & 1998 & $4 \times \operatorname{ext}$ & & 12 \\
\hline Jindo $^{3}$ & 344 & 1984 & 1998 & & & 4 \\
\hline Sohae $^{3}$ & 470 & 1993 & & $10 \times$ ext, $4 \times$ laser & & 6 \\
\hline Gwangan $^{3}$ & 500 & 1994 & & $3 \times$ ext, $1 \times$ laser & & 4 \\
\hline Youngjong $^{3}$ & 300 & 2000 & 2001 & $4 \times$ ext, $3 \times$ laser & & 10 \\
\hline Tsing $\mathrm{Ma}^{4}$ & 1377 & 1997 & $<1997$ & $10 \times$ level, $2 \times$ ext & 14 & \\
\hline Ting Kau ${ }^{4}$ & 475 & 1998 & $<1998$ & $2 \times$ ext & 7 & \\
\hline Kap Shui Mun $^{4}$ & 430 & 1997 & $<1997$ & $5 \times$ level, $2 \times$ ext & 6 & \\
\hline Stonecutters $^{2}$ & 1018 & 2009 & $<2009$ & $34 \times$ ext & 20 & \\
\hline
\end{tabular}

${ }^{1}$ (Ko and Ni 2005), ${ }^{2}$ (Sumitro 2001), ${ }^{3}$ (Koh et al. 2009) ${ }^{4}$ Wong 2007

Table 2: Humber Bridge deflection/load relationships from 1990/1991monitoring.

\begin{tabular}{|l|l|l|}
\hline Deflection component & Temperature $\mathrm{T} /{ }^{\circ} \mathrm{C}$ & Wind speed U/m/sec \\
\hline Vertical $\mathrm{v} / \mathrm{mm}$ & $\mathrm{v} \approx-60 \mathrm{~T}$ & $\mathrm{v} \approx-0.81 \mathrm{U}^{2}$ \\
\hline Rotation $\theta / \mathrm{milli}$-rad & & $\theta \approx 0.006 \mathrm{U} / \mathrm{U}$ \\
\hline Lateral $\mathrm{u} / \mathrm{mm}$ & $\mathrm{u} \approx 15 \mathrm{~T}$ & $\mathrm{u} \approx 1.18 \mathrm{U} \mid \mathrm{U}$ \\
\hline Longitudinal $\mathrm{w} / \mathrm{mm}$ & $\mathrm{w} \approx 8 \mathrm{~T}$ & \\
\hline
\end{tabular}



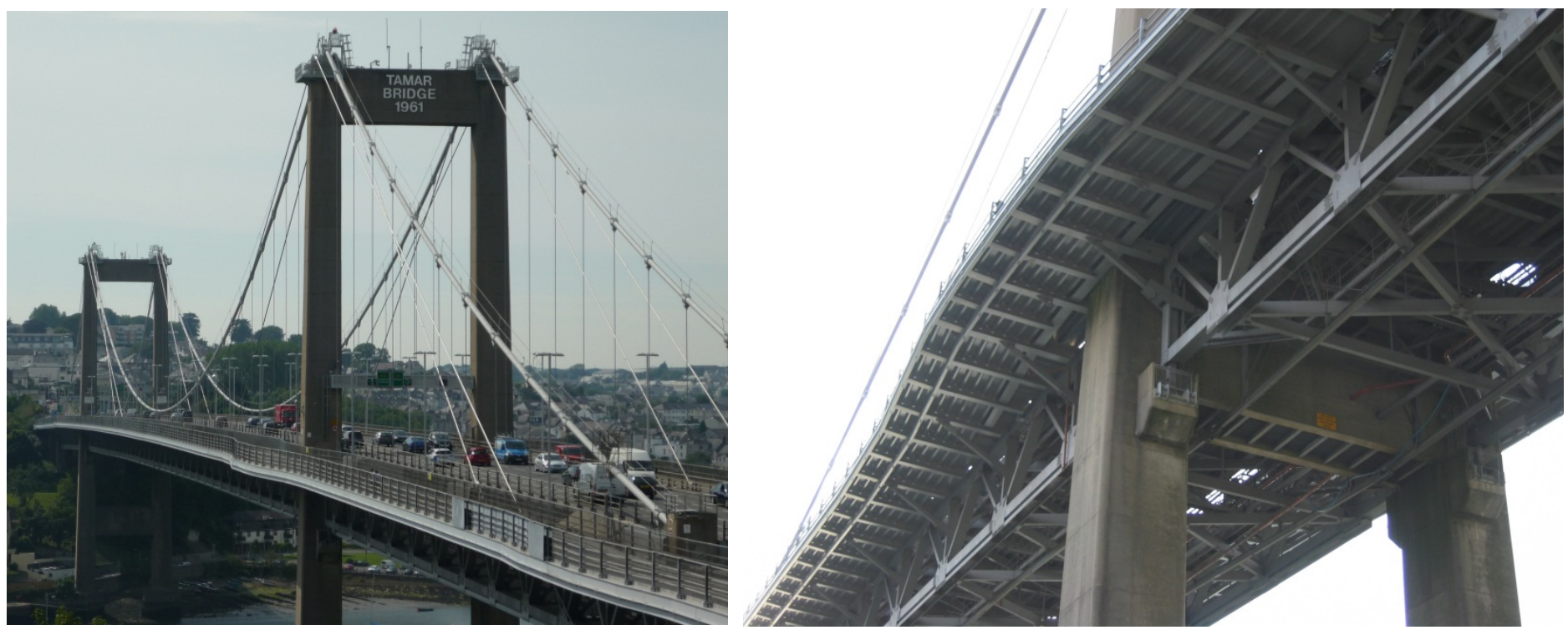

Figure 1: Tamar Bridge. Left showing additional stays and right showing cantilever and arrangements around Plymouth Tower. 

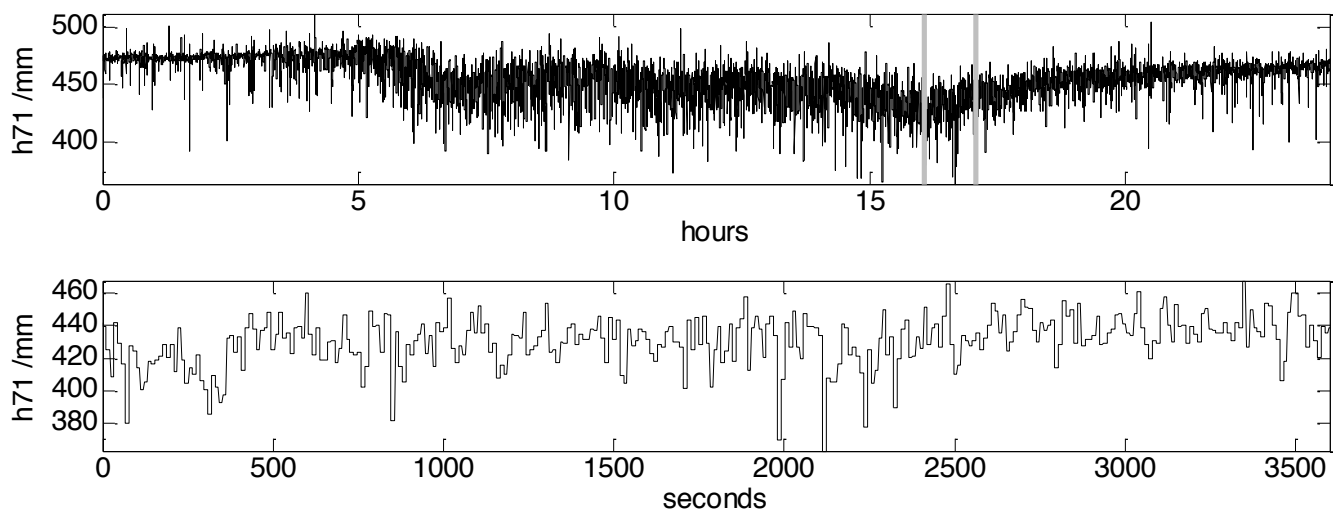

Figure 2: Level sensor data for one day and one hour. 


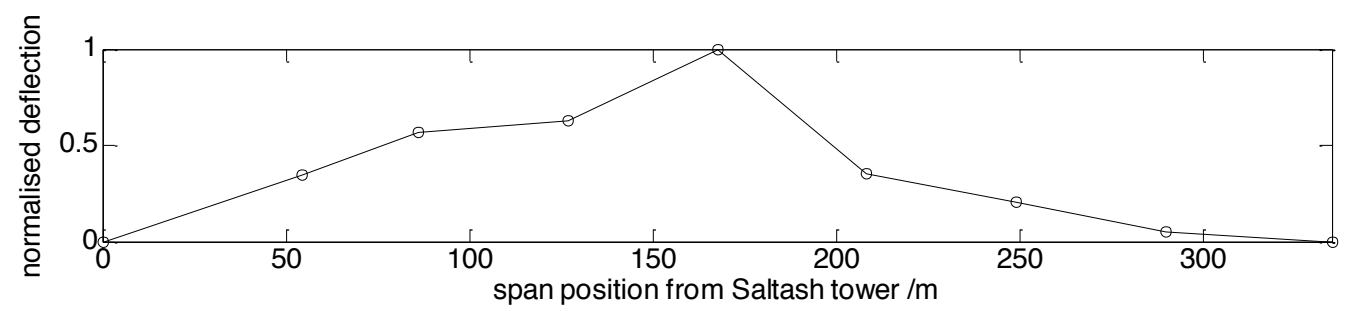

Figure 3: Vector for first principal component of level sensor time series. 


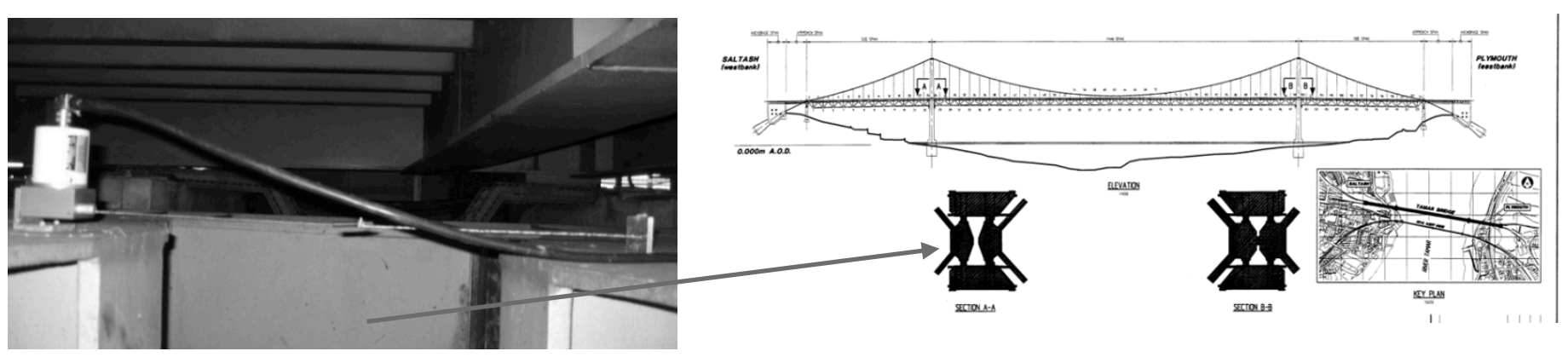

Figure 4: Extensometer (left) and location between Saltash and main spans (right). 

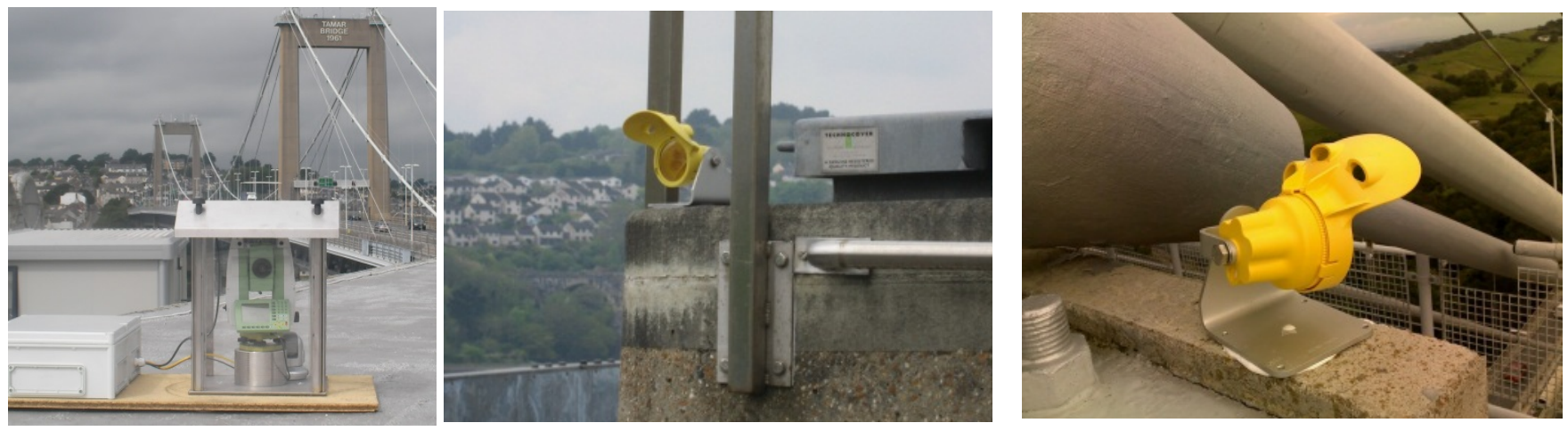

Figure 5: RTS unit on control room roof (left) and reflectors on Plymouth side tower (middle) and Saltash Tower (right). 

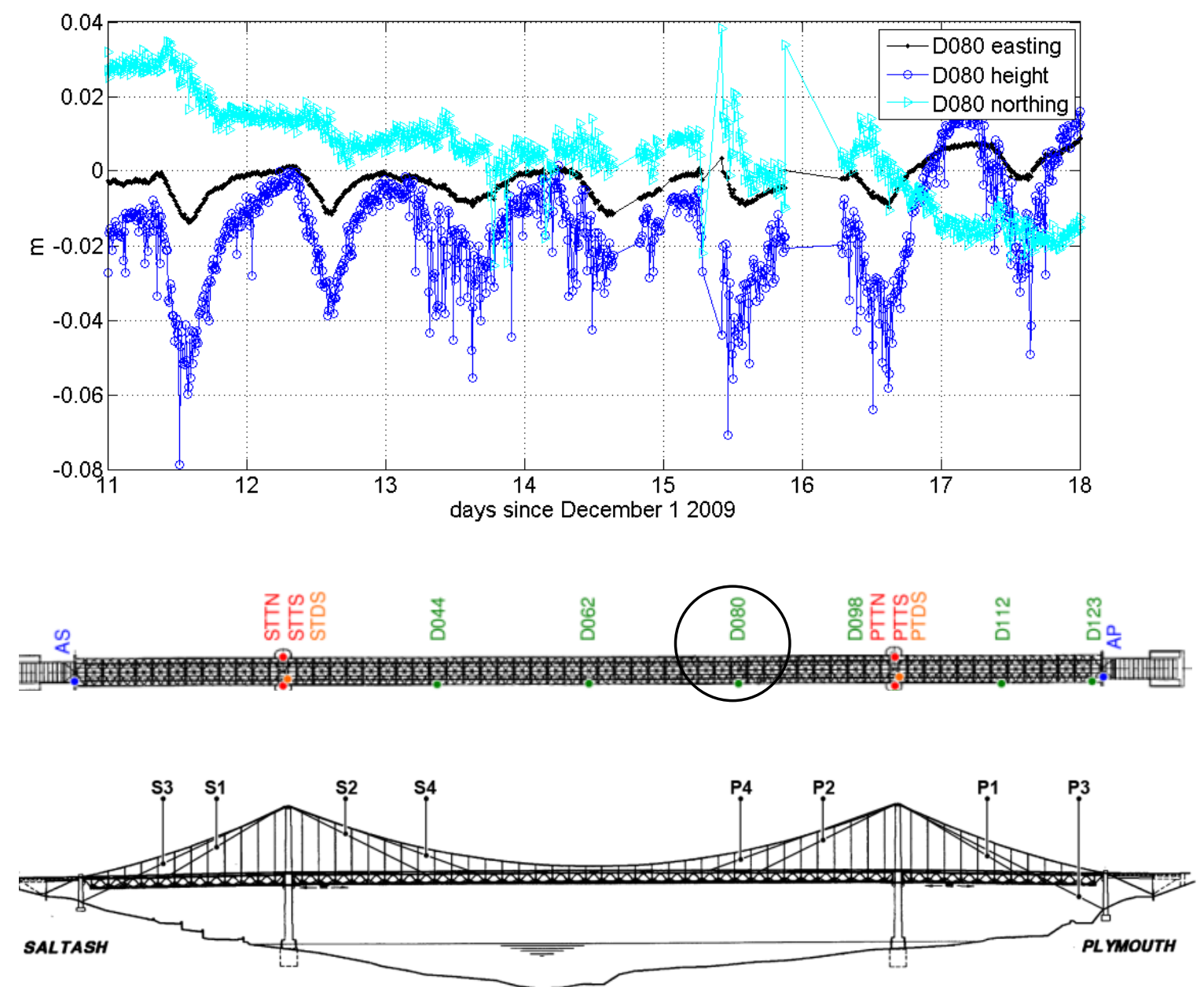

Figure 6: Reflector location plan, additional stay cable identities and deformation at location D080 (circled in plan). 

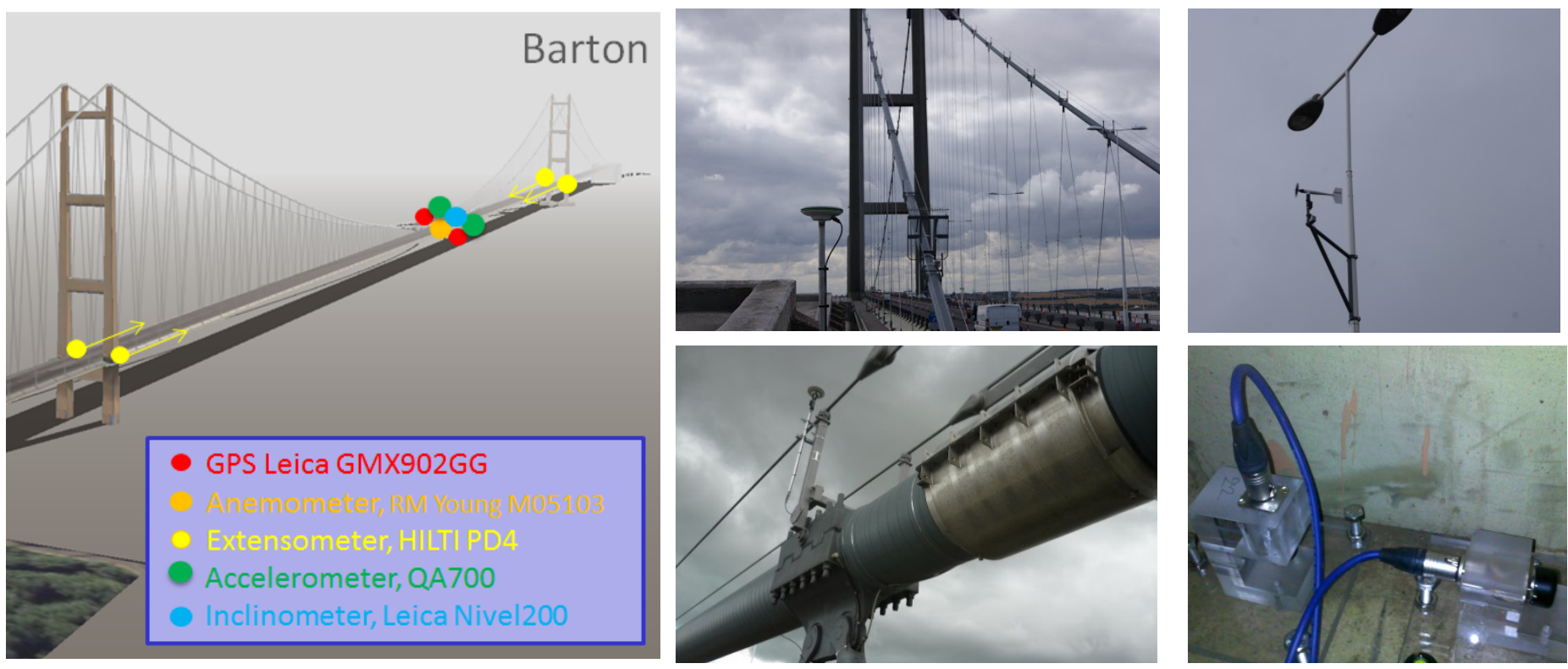

Figure 7: Humber Bridge (deformation) monitoring system and sensors: GPS antenna on anchorage and main cable; anemometer and accelerometers. 

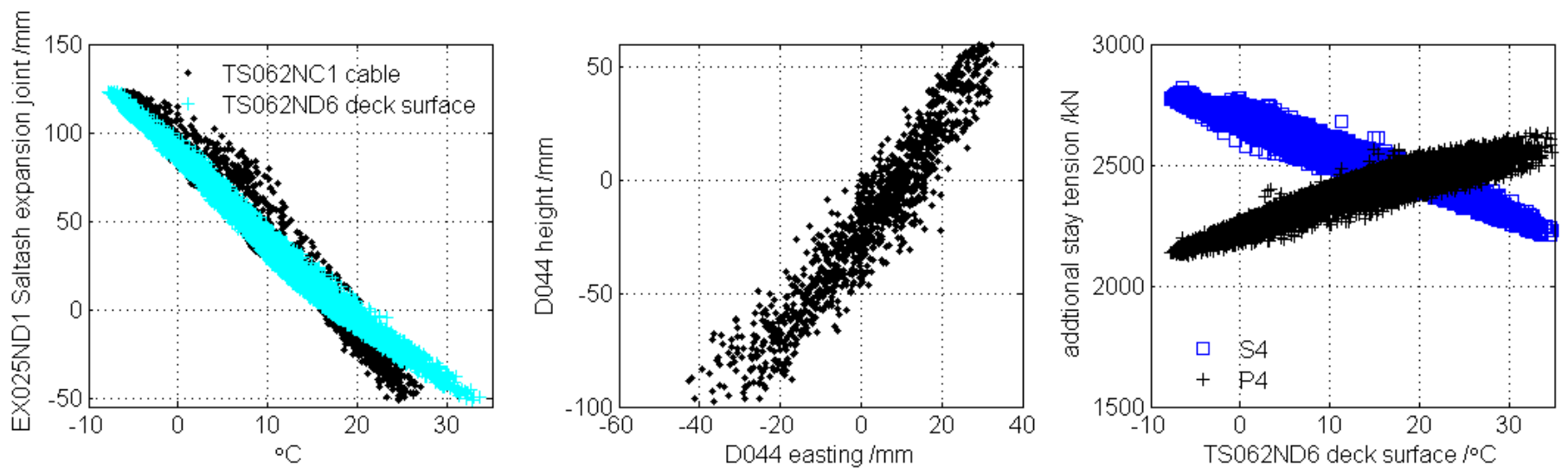

Figure 8: Tamar Bridge temperature effects on quasi-static deformation (see Figure 6 for stay cable locations). 

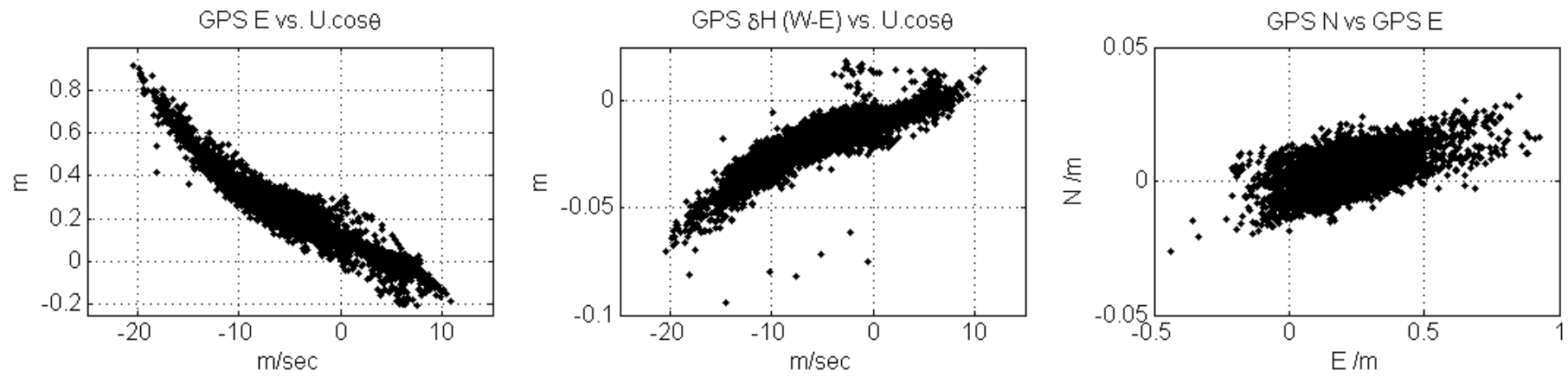

Figure 9: Humber Bridge: wind effects on quasi-static rotation and horizontal plane deformation. Positive wind is from the west. 

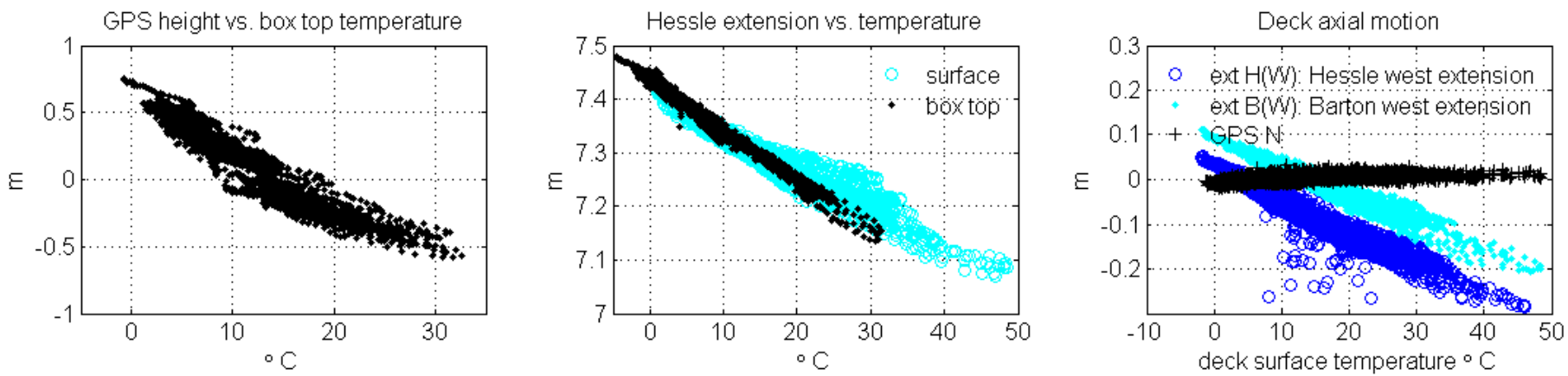

Figure 10: Humber Bridge: temperature effects on quasi-static deck vertical and axial movement. 

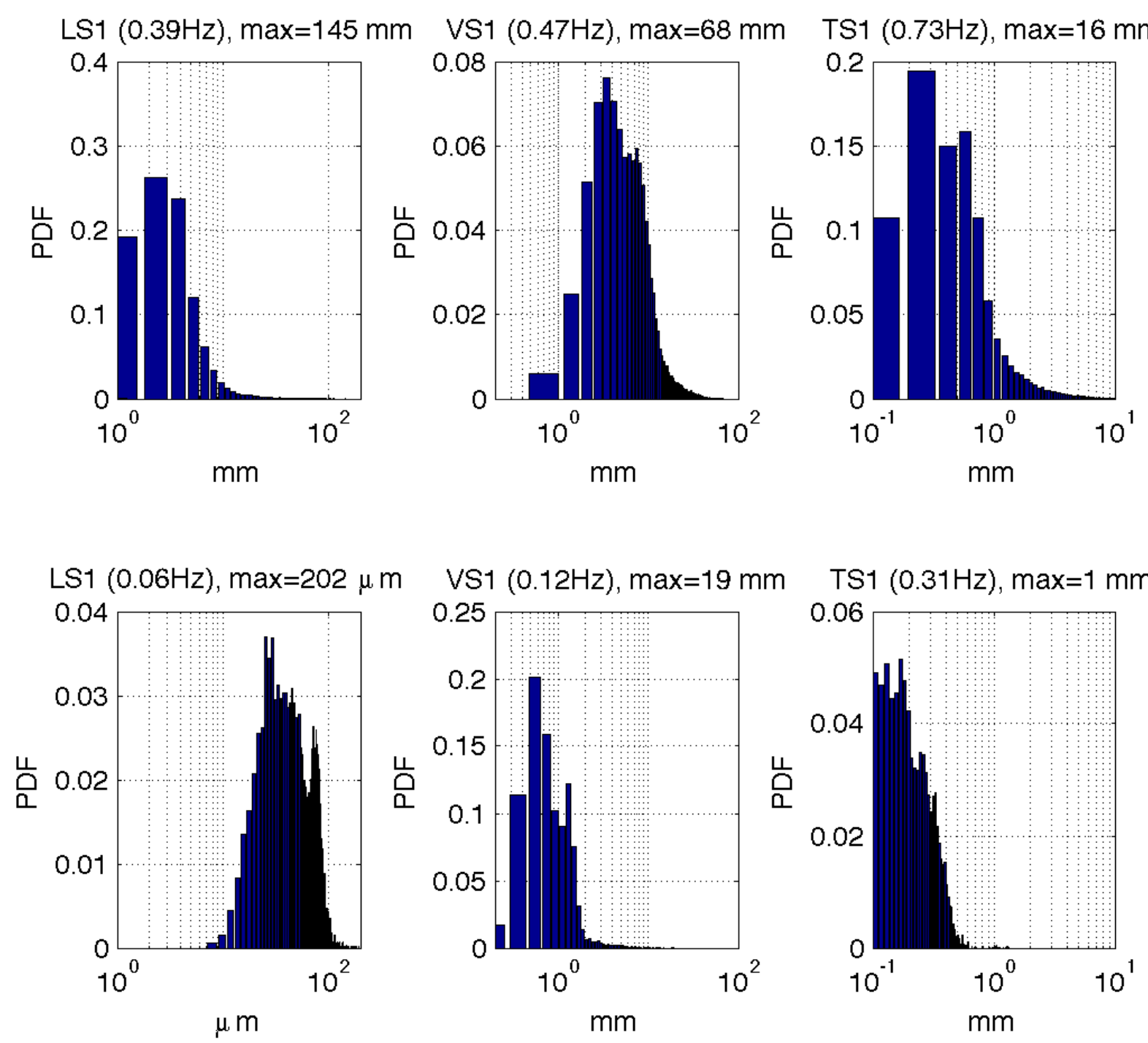

Figure 11 Probability density function of 30-minute modal root mean square displacements for Humber (upper) and Tamar (Lower) bridges for fundamental lateral (L), vertical (V) and torsions (T) symmetric (S) modes. Note the different units for Tamar LS1.
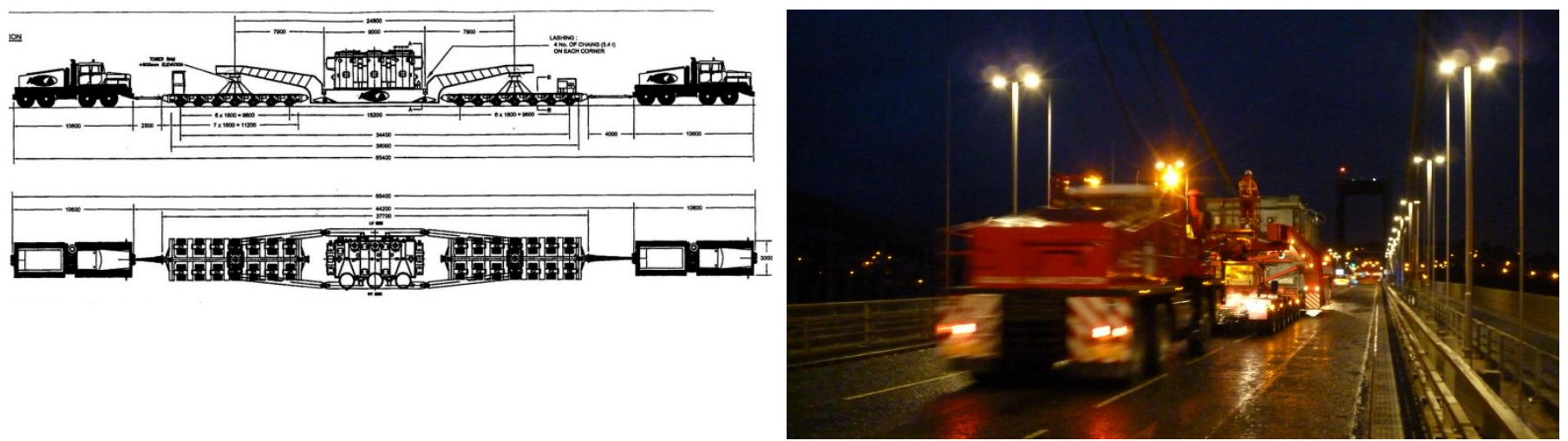
Figure 12: 300 tonne $65 \mathrm{~m}$ vehicle, westbound on Tamar Bridge, $31^{\text {st }}$ October 2010.
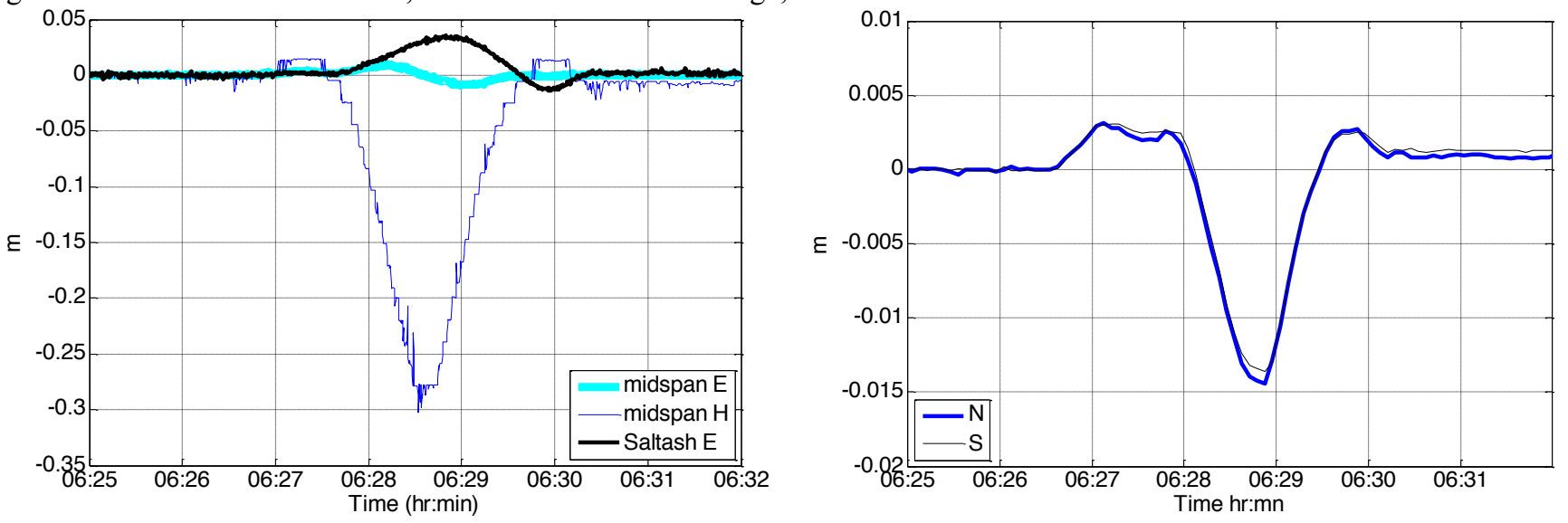
Figure 13: Passage of 300 tonne vehicle $31^{\text {st }}$ Oct 2010: RTS (left) and extensometer (right) data. Extension increases as deck moves away (to east) from Saltash Tower.
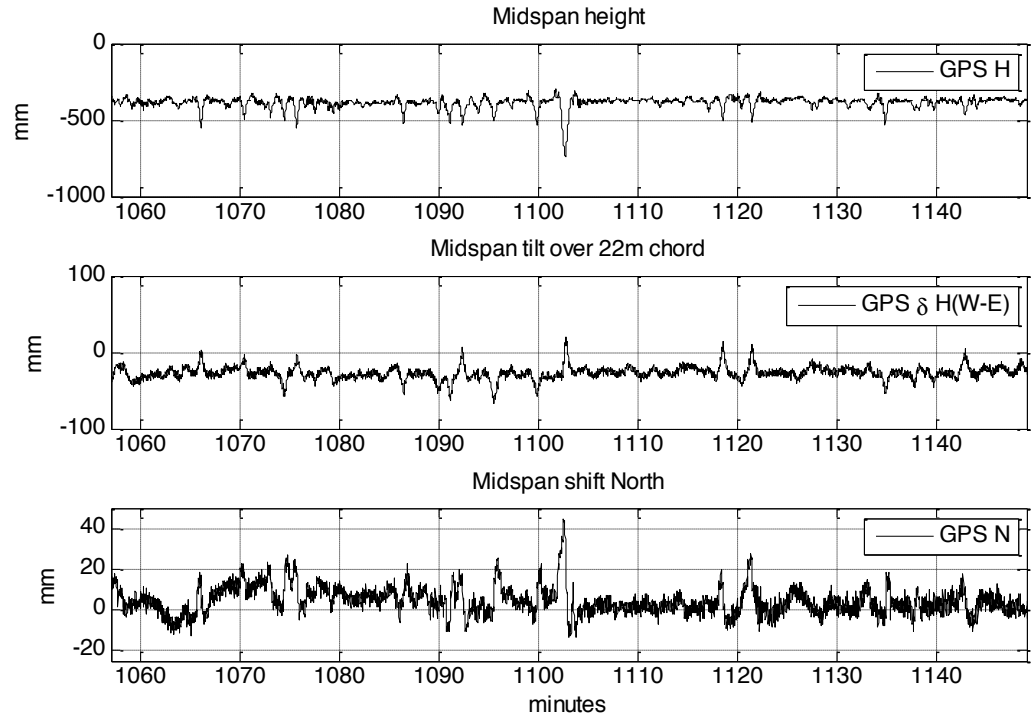

Figure 14: Humber Bridge. Passage of 110 tonne vehicle 7 August 2012 (at 1102 minutes).
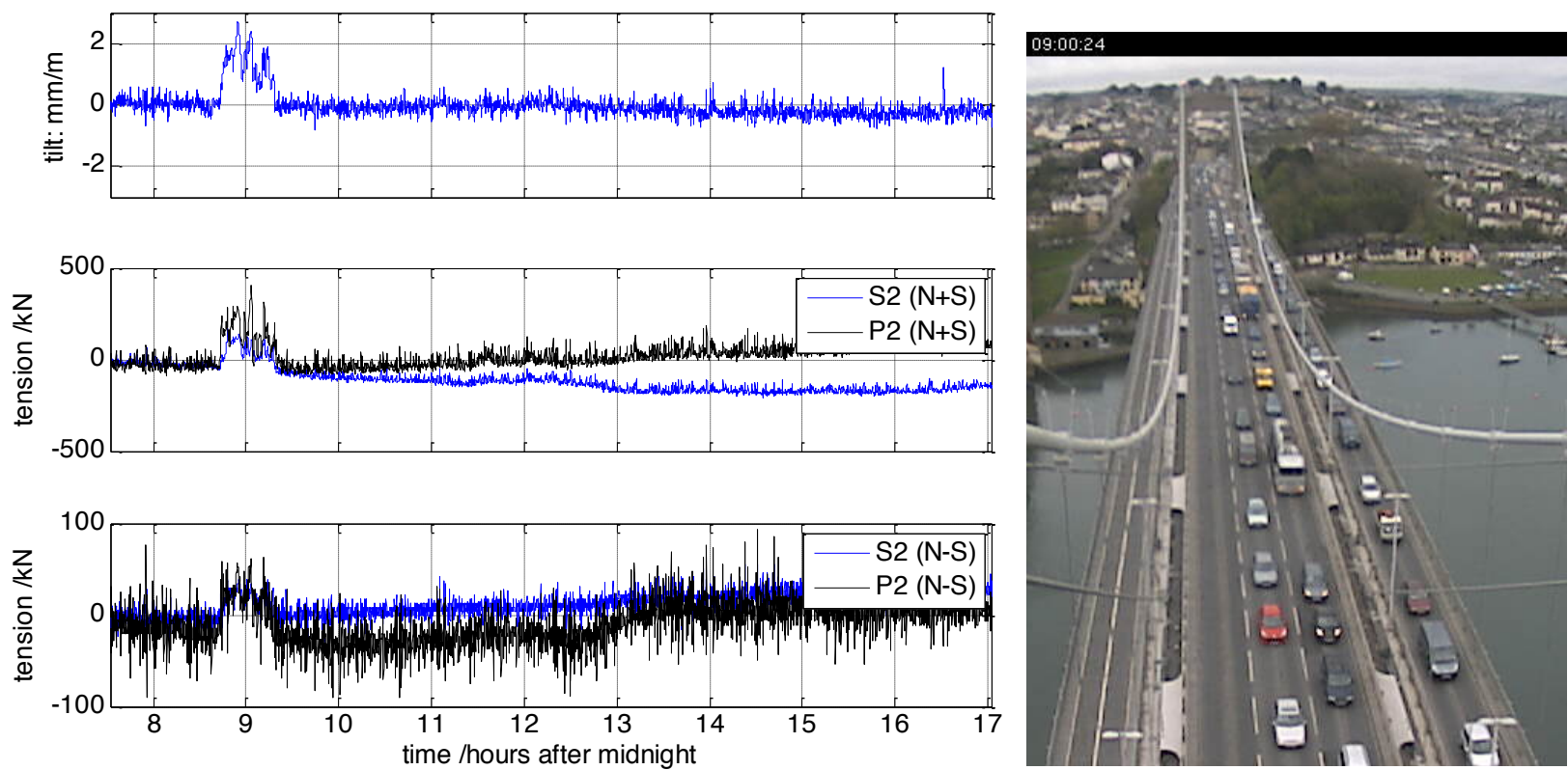

Figure 15: Tilt and main span cable tension changes at Tamar Bridge due to traffic jam (right) of vehicles travelling to Plymouth. 

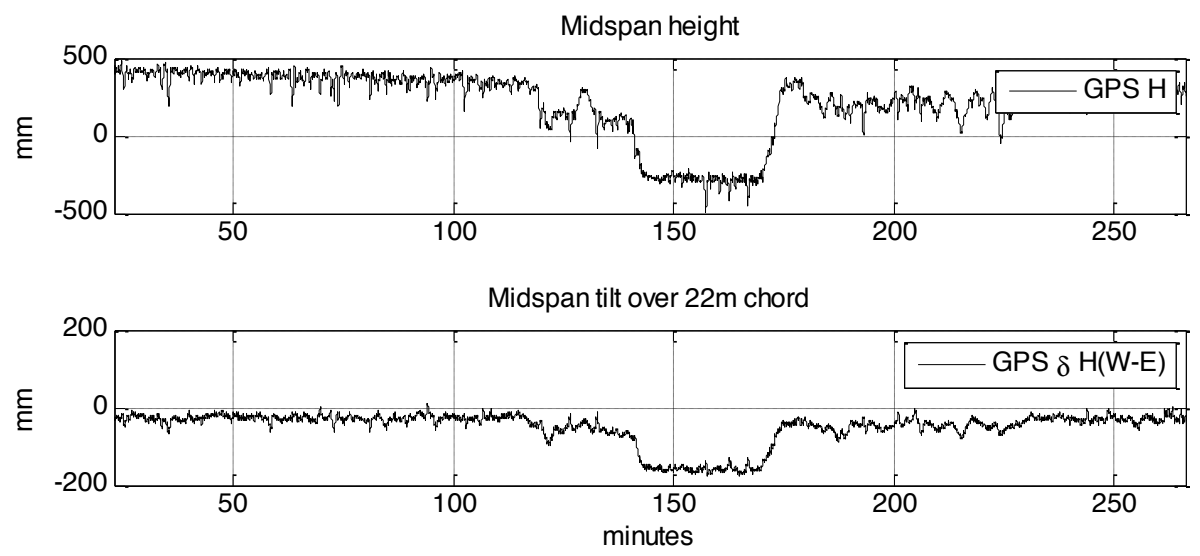

Figure 16: Vertical deformation and rotation at Humber Bridge due to traffic jam of northbound vehicles. 

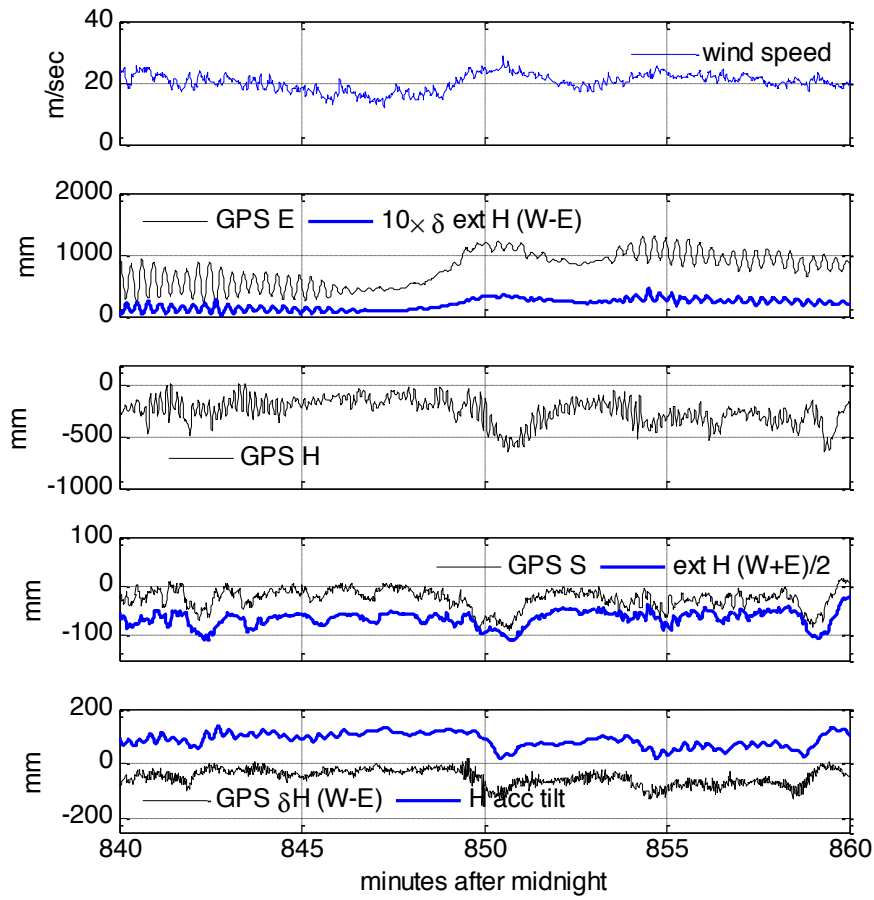
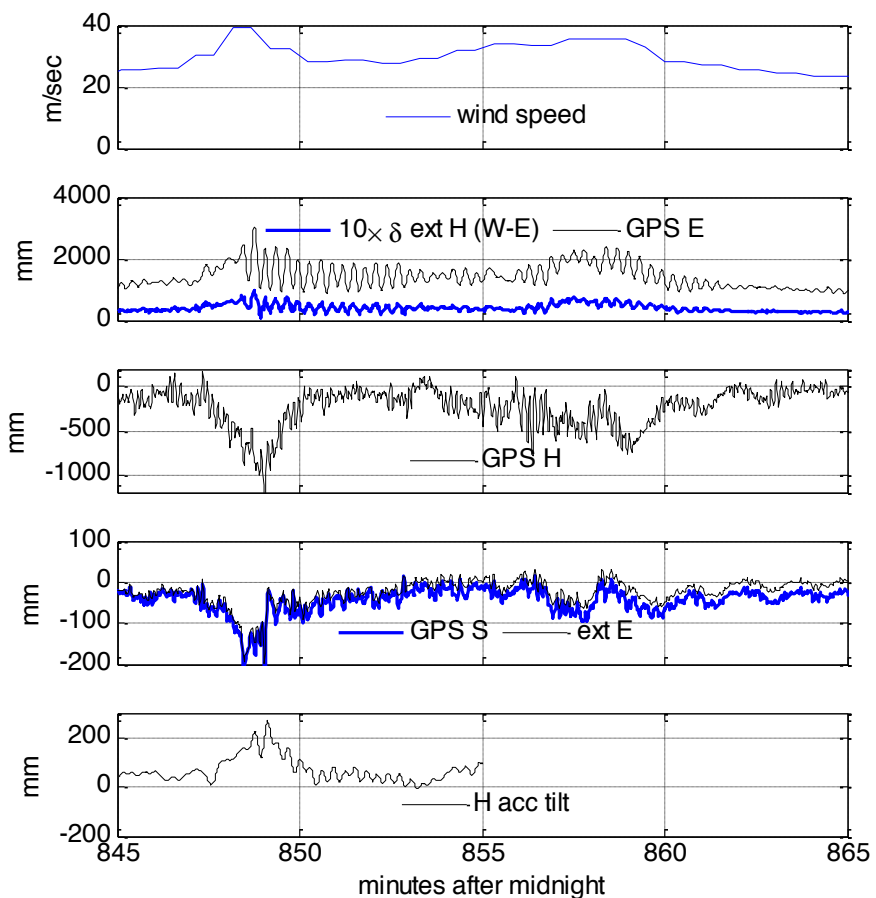

Figure 17: Humber Bridge. Time series of strong-wind response for $23^{\text {rd }}$ May 2011 and $30^{\text {th }}$ Jan 2013. 


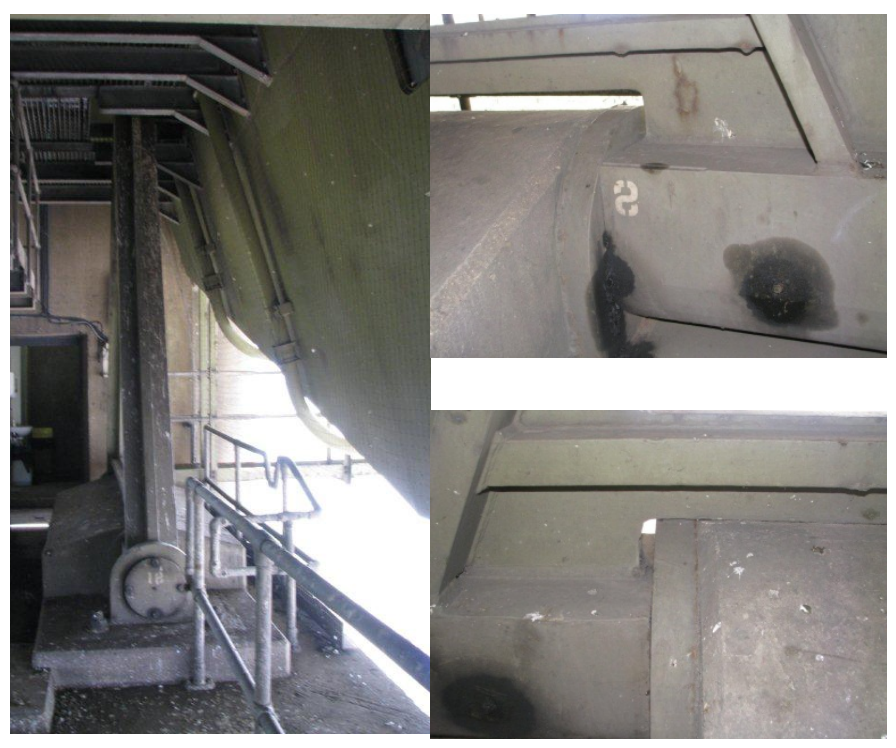

Figure 18: Hessle tower-main span west A-frame rocker (left) and close up of each of the two lower bearings showing different wear. The gap is has disappeared on one bearing due to excessive wear. 

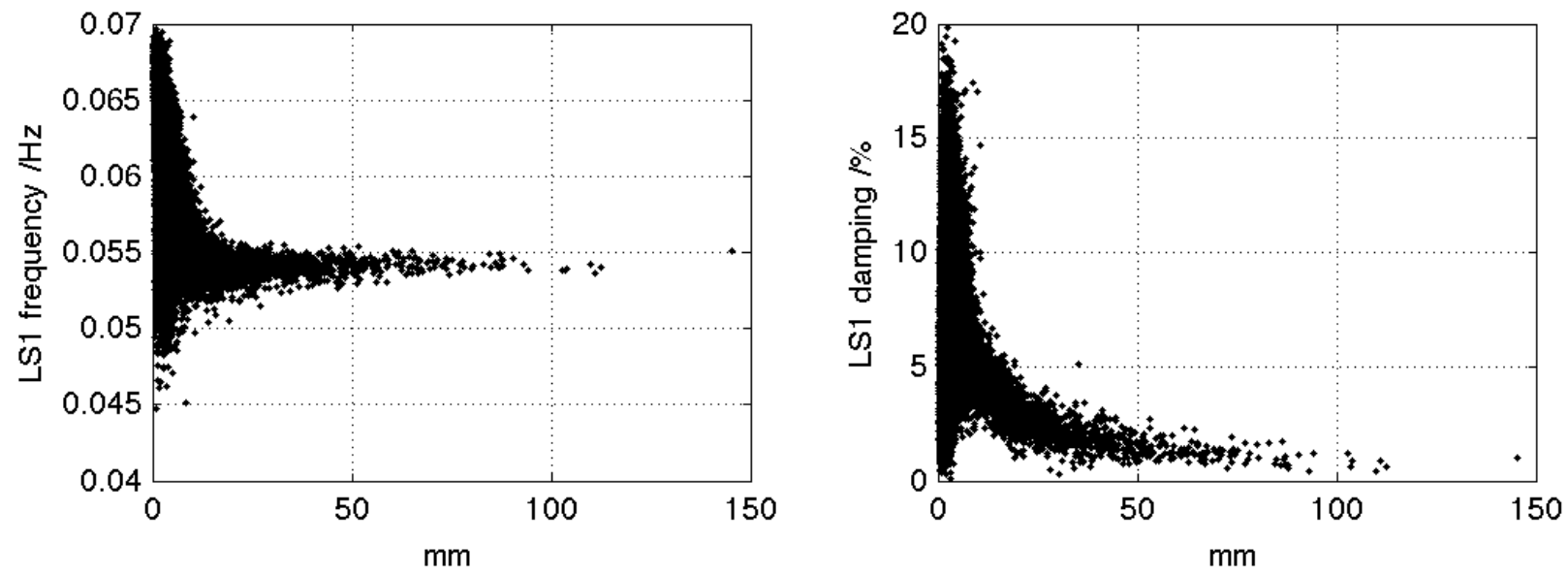

Figure 19: Frequency and damping estimates for fundamental lateral mode LS1 as a function of modal response. From 30-minute averages. 

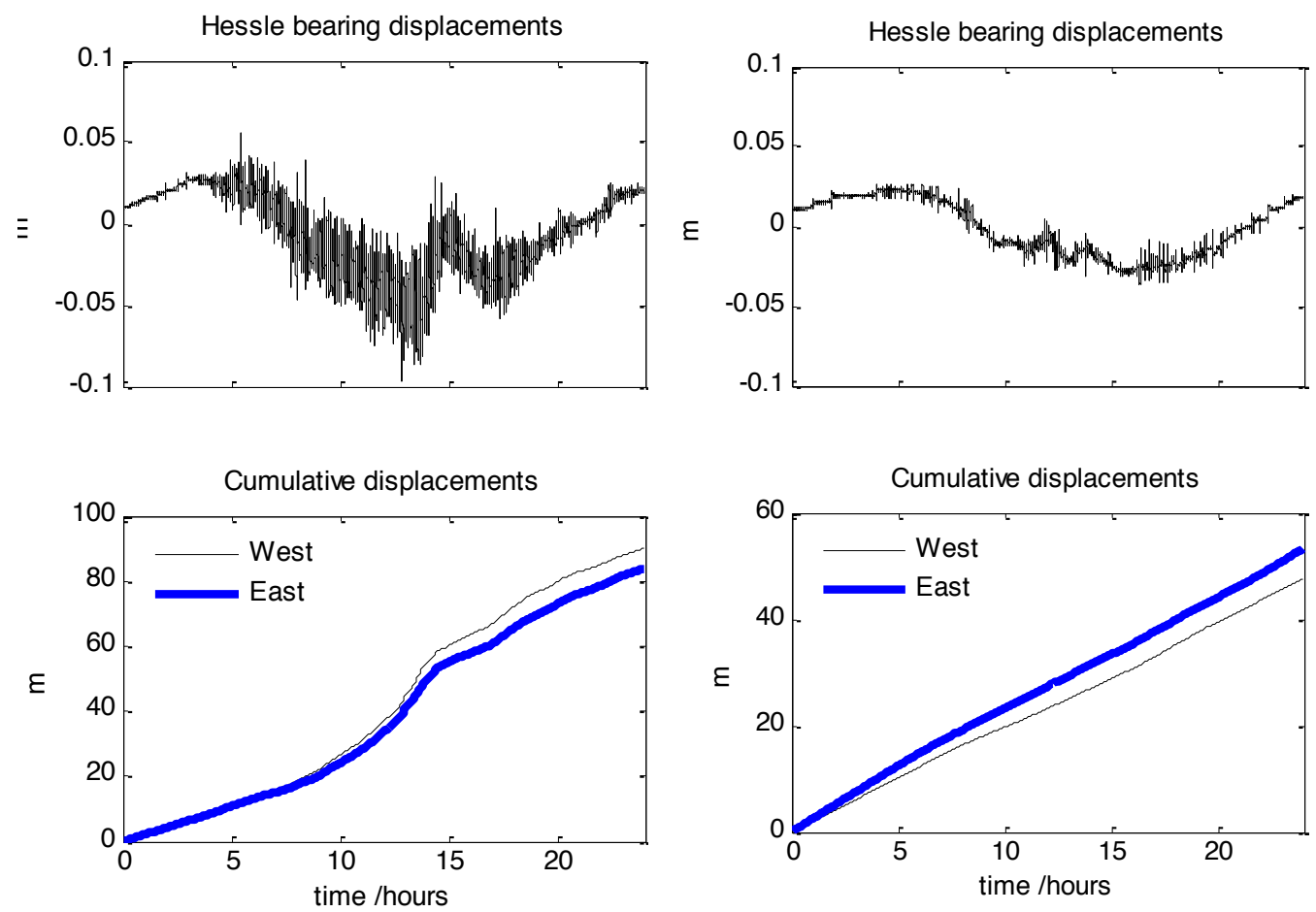

Figure 20: Humber Bridge. Bearing movements on windy (23 ${ }^{\text {rd }}$ May 2011) and calm day (19 ${ }^{\text {th }}$ June 2011). 

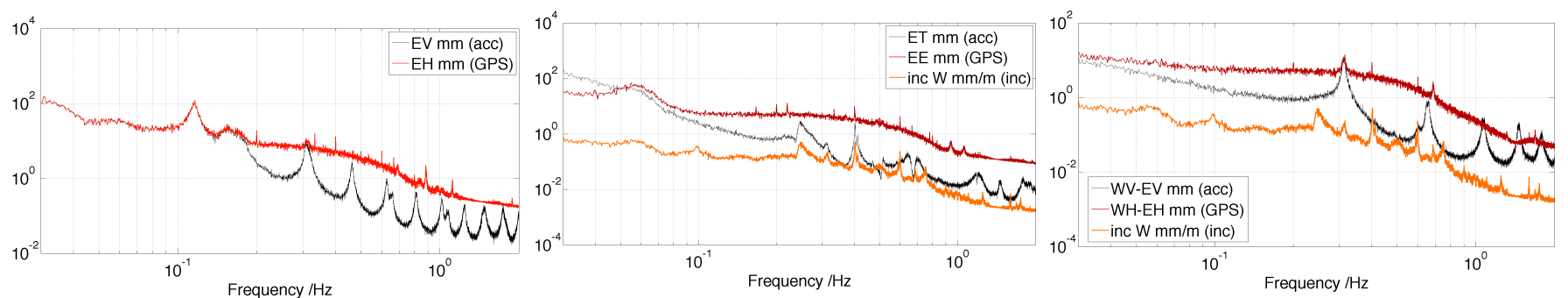

Figure 21 Humber Bridge, features of deformation response in frequency domain using different sensor types for a moderately windy day, $7^{\text {th }}$ October 2011. Left: Vertical displacement by accelerometer and GPS. Middle: Lateral displacement from accelerometer and GPS plus rotation angle from inclinometer. Right: Rotational displacement from accelerometer and GPS differences plus rotation angle from inclinometer. 

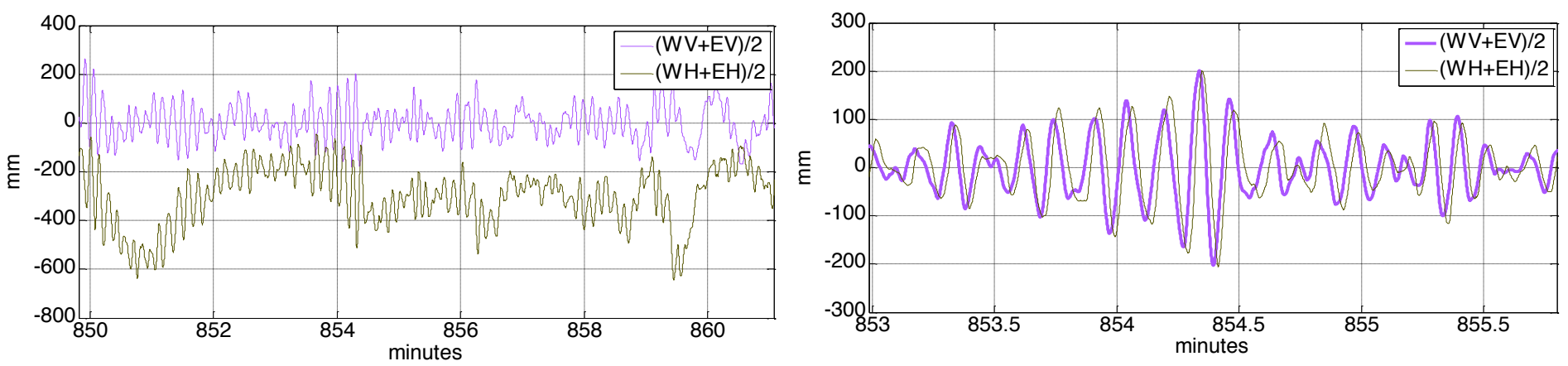

Figure 22: Humber Bridge. Comparison of integrated acceleration (V) and GPS (H) for $23^{\text {rd }}$ May 2011. Left has double-integrated acceleration with low pass filter at $0.0025 \mathrm{~Hz}$ and right with low pass filter at $0.08 \mathrm{~Hz}$ (leaving only dynamic components). 